\title{
Fluorine-functionalized metal-organic frameworks and porous coordination polymers
}

\author{
Shin-ichiro Noro ${ }^{1,2}$ and Takayoshi Nakamura ${ }^{1}$ \\ Fluorine, the element with the highest electronegativity and low electric polarizability, can produce a variety of characteristics, \\ including specific adsorption sites for molecules as well as flexibility to the host materials. In this review, we will introduce \\ fluorine-functionalized metal-organic frameworks/porous coordination polymers that show unique and unprecedented structures, \\ structural transformations, and gas and vapor adsorption/separation properties derived from the fluorine characteristics. \\ NPG Asia Materials (2017) 9, e433; doi:10.1038/am.2017.165; published online 29 September 2017
}

\section{INTRODUCTION}

During the last two decades, metal-organic frameworks (MOFs)/ porous coordination polymers (PCPs) composed of metal ions and organic bridging ligands as main building units and, in some cases, inorganic ligands, have been investigated extensively because of their versatile structural diversity, high structural controllability (pore size, shape, dimension, flexibility and surface environment), high crystallinity, and their potential porous properties/functionalities in a variety of research fields such as storage and separation, catalysis, drug delivery and sensing ability. ${ }^{1-3}$ The porous properties of MOFs/PCPs can be finely tailored by not only chemical modification of organic ligands and judicious choice of components but also a variety of techniques such as solid solution formation, defect engineering, core-shell structure, crystal morphology and size control, and so on. For example, the appropriate combination of organic bridging ligands provided the $\mathrm{Zn}$ (II) MOF, $\quad\left[\mathrm{Zn}_{4} \mathrm{O}(\mathrm{bte})_{4 / 3}(\mathrm{bpdc})\right] \quad\left(\mathrm{bte}=4,4^{\prime}, 4^{\prime \prime}\right.$-[benzene-1,3,5-triyl-tris (ethyne-2,1-diyl)] tribenzoate, bpdc = biphenyl-4,4'-dicarboxylate), with ultra-high Brunauer-Emmett-Teller and Langmuir specific surface areas close to 6000 and $10000 \mathrm{~m}^{2} \mathrm{~g}^{-1}$, respectively. ${ }^{4}$ Unlike porous inorganic zeolites and porous carbon materials, MOFs often give flexible structures. As coordination bonds, hydrogen bonds and van der Waals interactions that are used to assemble each component are weaker (bonding energies are $10 \sim 200 \mathrm{~kJ} \mathrm{~mol}^{-1}$ ) than covalent and ionic bonds $\left(200 \sim 1000 \mathrm{~kJ} \mathrm{~mol}^{-1}\right)$, reversible rotation, bending and breaking of these weaker bonds easily occurs, resulting in structural changes. One representative of flexible MOFs is $[\mathrm{Cr}(\mathrm{OH})(1,4-\mathrm{bdc})]$ (MIL-53(Cr), 1,4-bdc = 1,4-benzenedicarboxylate), in which local reorientation of the coordination bond triggered by guest adsorption/ desorption induced the structural transformation between narrow pore and large pore forms. ${ }^{5}$ In addition, many MOFs show high crystallinity as with porous inorganic zeolites, which is advantageous for understanding deeply the structure-property relationship using single-crystal and powder X-ray diffraction techniques. For example, the unprecedented highly selective $\mathrm{CO}$ sorption from a $\mathrm{CO} / \mathrm{N}_{2}$ mixture, which is difficult to separate, was achieved using the flexible $\mathrm{Cu}(\mathrm{II}) \mathrm{MOF}$, $[\mathrm{Cu}$ (aip) $]$ (aip $=5$-azidoisophthalate). ${ }^{6}$ Successful determination of the crystal structures of the dried and $\mathrm{CO}$-adsorbed forms using powder $\mathrm{X}$-ray diffraction demonstrated that the synergetic effect of the interaction between $\mathrm{CO}$ and the $\mathrm{Cu}(\mathrm{II})$ axial sites and a structural transformation contributed to such high selectivity.

At present, it is all but impossible to comprehend completely the reports on MOFs because of the huge, ever-growing number of reports that have been published. In this review article, therefore, we focused on fluorine-functionalized MOFs/PCPs due to their fluorine-specific, interesting porous properties. A fluorine atom has discriminating characteristics, the highest electronegativity and small electric polarizability, which causes the development of a variety of unique characteristics, such as low boiling point, fluorous phase, selective gas absorbability, hydrophobicity and high chemical stability, in fluorine-containing molecules/materials. One of the best-known fluorine-containing materials is polytetrafluoroethylene, an organic polymer containing only carbon and fluorine atoms invented by the DuPont company. Polytetrafluoroethylene exhibits high thermal and chemical stability, low dielectric constant, high insulation property, high water and oil repellency, and non-adhesive property, all of which are caused by fluorine atoms, and is used extensively in our society.

In 2014, Pachfule and Banerjee ${ }^{7}$ published an excellent review article on fluorine-functionalized MOFs/PCPs, in which MOFs/PCPs with a variety of fluorine-containing building blocks and their structure-property (gas adsorption and separation) relationships were introduced. Herein, we provides a comprehensive review of fluorinefunctionalized MOFs/PCPs including not only latest results on the basis of the kinds of fluorinated building blocks but also a much wider range of fluorine-related properties (hydrophobicity, adsorption/ separation, perfluoroarene-arene interaction, structural flexibility, ionic conductivity and low-energy $\mathrm{C}-\mathrm{F}$ bond). The fluorinated components, crystal structures and porous properties of fluorinefunctionalized MOFs/PCPs are discussed with the relations between

\footnotetext{
${ }^{1}$ Research Institute for Electronic Science, Hokkaido University, Sapporo, Japan and ${ }^{2}$ Creative Research Institute, Hokkaido University, Sapporo, Japan Correspondence: Professor S Noro, Research Institute for Electronic Science, Hokkaido University, N20W10, Kita-ku, Sapporo 001-0020, Japan. E-mail: noro@es.hokudai.ac.jp 
<smiles>Fc1c(F)c(Cc2ccncc2)c(F)c(F)c1Cc1ccncc1</smiles>

b<smiles>Fc1c(F)c(-c2c(F)c(F)c(Cc3ccncc3)c(F)c2F)c(F)c(F)c1Cc1ccncc1</smiles><smiles>Fc1c(Cc2ccncc2)c(F)c2c(F)c(Cc3ccncc3)c(F)c(F)c2c1F</smiles>

d<smiles>Fc1c(Cc2ccncc2)c(F)c2c(F)c(Cc3ccncc3)c(F)c(F)c2c1F</smiles>

Figure 1 Fluorine-substituted organic ligands with the pyridine coordination sites reported by Fujita and colleagues. ${ }^{8,47}$

a
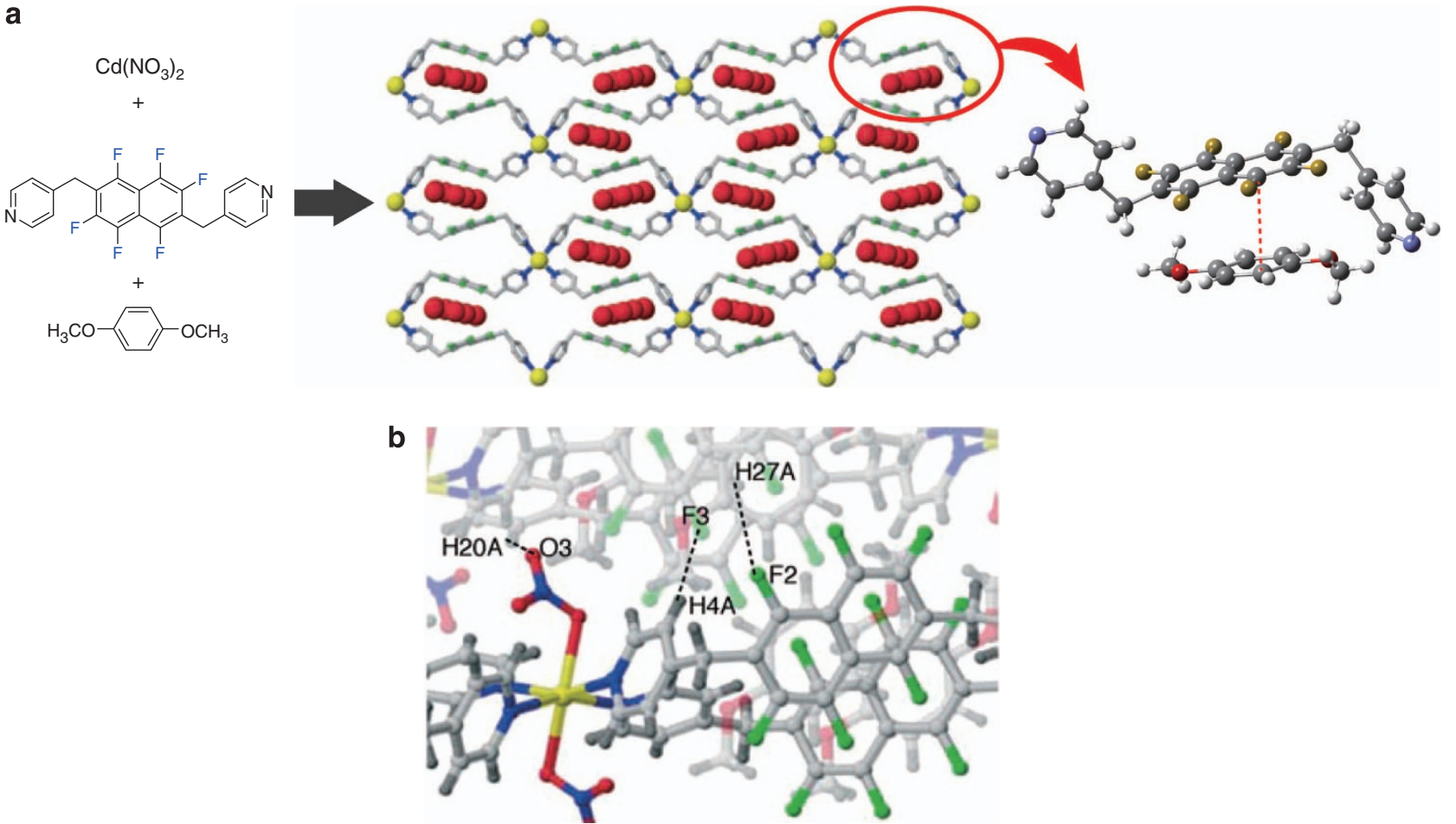

Figure 2 Crystal structure of $\left\{\left[\mathrm{Cd}\left(\mathrm{NO}_{3}\right)_{2}(2,6-\mathrm{bpfn})_{2}\right] \cdot 2\right.$ (p-dimethoxybenzene) $\}$. (a) Top view of the two-dimensional sheet. The guest $p$-dimethoxybenzene molecules are coloured red. (b) View of the intermolecular hydrogen bonds. Reproduced from Kasai et al. ${ }^{8}$

porous properties and fluorine characters. The papers that did not discuss on fluorine-porous property relationships in fluorinefunctionalized MOFs/PCPs are not covered here. Table 1 summarizes fluorine-functionalized MOFs/PCPs introduced in this review.

\section{MOFS CONTAINING FLUORINE- AND TRIFLUOROMETHYL- SUBSTITUTED ORGANIC LIGANDS}

It is well known that a perfluoroarene unit forms an intermolecular face-to-face perfluoroarene-arene interaction (the origins of which are van der Waals and quadrupole-quadrupole interactions) with an arene unit. $^{46}$ Fujita and colleagues ${ }^{8,47}$ reported the crystal structures of a large number of $\mathrm{Cd}(\mathrm{II}) \mathrm{MOF}$ with fluorine-functionalized organic ligands, as shown in Figure 1. The observed MOFs formed one-, two- and three-dimensional porous structures with non-fluorinated aromatic guest molecules, some of which formed intermolecular arene-perfluoroarene interactions between fluorinated ligands and non-fluorinated aromatic guests. For example, the two-dimensional MOF, $\left\{\left[\mathrm{Cd}\left(\mathrm{NO}_{3}\right)_{2}(2,6-\mathrm{bpfn})_{2}\right] \cdot 2(p\right.$-dimethoxybenzene $\left.)\right\} \quad(2,6-\mathrm{bpfn}=$ 2,6-bis(4-pyridylmethyl)hexafluoronaphthalene, Figure 1c), exhibited face-to-face interactions between the perfluoroarene rings and the guest arene rings with the shortest $\mathrm{C} \cdot{ }^{\circ} \mathrm{C}$ distance of $3.411 \AA$ inside the grids (Figure $2 \mathrm{a}$ ). ${ }^{8}$ In addition, the guest afforded the weak $\mathrm{C}-\mathrm{H} \bullet \bullet \mathrm{F}$ hydrogen bond $(\mathrm{H} \bullet \bullet \mathrm{F}$ distance $=2.653 \AA$ and $\mathrm{C}-\mathrm{H} \bullet \bullet \cdot \mathrm{F}$ angle $=$ $\left.126.1^{\circ}\right)$ with the neighboring two-dimensional sheet $(\mathrm{H} 27 \mathrm{~A} \bullet \bullet \mathrm{F} 2$ in Figure 2b)..$^{48}$

The polar $\mathrm{C}-\mathrm{F}$ bond may be useful for a preferable gas adsorption site. Cheetham and colleagues ${ }^{9}$ found an enhanced enthalpy of $\mathrm{H}_{2}$ adsorption in the three-dimensional fluorinated MOF, $\left\{\left[\mathrm{Zn}_{5} \text { (triazole }\right)_{6}\right.$ 


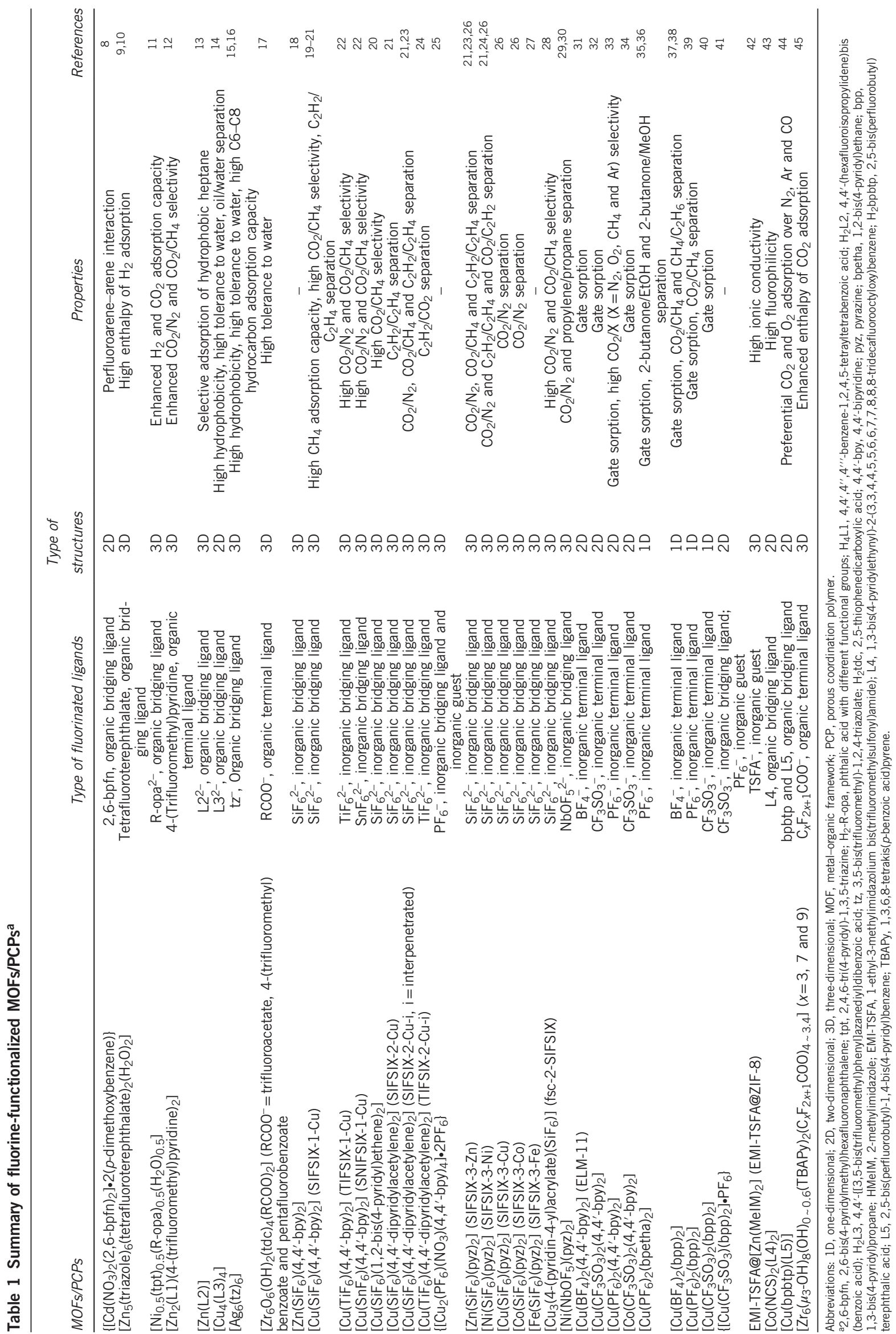


a<smiles>O=C(O)c1c(F)c(F)c(C(=O)O)c(F)c1F</smiles>

b<smiles>O=C(O)c1cccc(F)c1C(=O)O</smiles>

C<smiles>O=C(O)c1c(F)ccc(F)c1C(=O)O</smiles><smiles>O=C(O)c1c(F)c(F)c(F)c(F)c1C(=O)O</smiles>

e<smiles>FC(F)(F)c1ccncc1</smiles>

f<smiles>O=C(O)c1ccc(C(c2ccc(C(=O)O)cc2)(C(F)(F)F)C(F)(F)F)cc1</smiles>

g<smiles>O=C(O)c1ccc(N(c2ccc(C(=O)O)cc2)c2ccc(C(F)(F)F)cc2)cc1</smiles>

h i<smiles>O=C(O)C(F)(F)F</smiles>

j<smiles>O=C(O)c1ccc(C(F)(F)F)cc1</smiles>

k<smiles>O=C(O)c1c(F)c(F)c(F)c(F)c1F</smiles>

Figure 3 Molecular structures of organic ligands with fluorine or trifluoromethyl substituents, (a) tetrafluoroterephthalic acid, (b) 3-fluorophthalic acid, (c) 3,6-difluorophthalic acid, (d) 3,4,5,6-tetrafluorophthalic acid, (e) 4-(trifluoromethyl)pyridine, (f) 4,4'-(hexafluoroisopropylidene)bis(benzoic acid), (g) 4,4'$\{[3,5$-bis(trifluoromethyl)phenyl]azanediyl\}dibenzoic acid, (h) 3,5-bis(trifluoromethyl)-1,2,4-triazole, (i) trifluoroacetic acid, (j) 4-(trifluoromethyl)benzoic acid and $(\mathbf{k})$ pentafluorobenzoic acid.

(tetrafluoroterephthalate $\left.\left.)_{2}\left(\mathrm{H}_{2} \mathrm{O}\right)_{2}\right] \bullet 4 \mathrm{H}_{2} \mathrm{O}\right\}$, using commercially available fluorinated tetrafluoroterephthalic acid (Figure 3a). This MOF had a small pore and fluorine atoms exposed on the pore surface (Figure 4a), which was expected to cause high enthalpy of $\mathrm{H}_{2}$ adsorption $\left(-8 \mathrm{~kJ} \mathrm{~mol}^{-1}\right.$ at low coverage, Figure $\left.4 \mathrm{~b}\right)$, comparable to MOFs with coordinatively unsaturated metal centers that considerably increase this value. After this report, the $\mathrm{H}_{2}$ adsorption sites were closely investigated using inelastic neutron scattering spectroscopy and molecular simulation by Space and colleagues. ${ }^{10}$ Theoretical calculation is a powerful tool to support and predict intermolecular interactions between coordination frameworks and guest molecules. The inelastic neutron scattering spectroscopy and simulation results concluded that the most favorable adsorption site is the vicinity of the $\mathrm{Zn}$-coordinated $\mathrm{H}_{2} \mathrm{O}$, the fluorine and the carboxylate oxygen atoms of tetrafluoroterephthalate ligands in small pores as shown in Figure 4c. To elucidate the effect of fluorination on the gas-sorption properties of MOFs, a systematic investigation was performed by $\mathrm{Bu}$ and colleagues ${ }^{11}$ using the three-dimensional MOFs, $\left\{\left[\mathrm{Ni}_{0.5}(\mathrm{tpt})_{0.5}\right.\right.$ $\left.(\mathrm{R} \text {-opa })_{0.5}\left(\mathrm{H}_{2} \mathrm{O}\right)_{0.5}\right] \cdot x$ (guest) $\} \quad(\mathrm{tpt}=2,4,6$-tri(4-pyridyl)-1,3,5-triazine and $\mathrm{H}_{2}$-R-opa = phthalic acid with different functional groups), in which each phthalate and tpt ligand bridges two and three $\mathrm{Ni}(\mathrm{II})$ ions, respectively, to form the porous framework. The increase in the number of fluorine atoms from 3-fluorophthalic acid, 3,6-difluorophthalic acid to 3,4,5,6-tetrafluorophthalic acid (Figure $3 \mathrm{~b}-\mathrm{d}$ ) resulted in the positive effect of fluorine on $\mathrm{H}_{2}$ and $\mathrm{CO}_{2}$ adsorption capacity. Snurr and colleagues ${ }^{12}$ succeeded in the enhancement of $\mathrm{CO}_{2} / \mathrm{N}_{2}$ and $\mathrm{CO}_{2} / \mathrm{CH}_{4}$ selectivities in the three-dimensional
MOF, $\left[\mathrm{Zn}_{2}(\mathrm{~L} 1)\right] \quad\left(\mathrm{H}_{4} \mathrm{~L} 1=4,4^{\prime}, 4^{\prime \prime}, 4^{\prime \prime \prime}\right.$-benzene-1,2,4,5-tetrayltetrabenzoic acid), using the fluorinated 4-(trifluoromethyl)pyridine terminal ligand (Figure $3 \mathrm{e}$ ). The as-synthesized sample had paddlewheel $\mathrm{Zn}_{2}$ dimers and the $\mathrm{N}, \mathrm{N}$-dimethylformamide (DMF) molecules were coordinated to their axial sites. Using the post-synthetic modification approach, the coordinated DMF could be successfully exchanged with the bigger 4-(trifluoromethyl)pyridine. Although this exchange led to a lower specific surface area ( 800 vs $390 \mathrm{~m}^{2} \mathrm{~g}^{-1}$ ), the $\mathrm{CO}_{2} / \mathrm{N}_{2}$ and $\mathrm{CO}_{2} /$ $\mathrm{CH}_{4}$ selectivities increased, especially remarkably higher $\mathrm{CO}_{2} / \mathrm{N}_{2}$ selectivity at low pressure (22 vs 42 (ideal adsorbed solution theory (IAST) selectivity for equimolar binary mixture)), at the same time. The authors proposed that this enhancement in selectivity can be attributed to (1) the attractive interaction between the polar $\mathrm{CF}_{3}$ group and $\mathrm{CO}_{2}$ and (2) the formation of smaller pores by the introduction of more bulky 4-(trifluoromethyl)pyridine ligands.

The hydrophobic character of the fluorinated pore surface provides a preferable adsorption and a high capacity of hydrophobic guests. Monge et al. ${ }^{13}$ reported the three-dimensional MOF $[\mathrm{Zn}(\mathrm{L} 2)]\left(\mathrm{H}_{2} \mathrm{~L} 2\right.$ is shown in Figure $3 \mathrm{f}$ ), in which the helical $\mathrm{Zn}$ (II)-carboxylate chains are connected by the L2 ligands to form two kinds of very different parallel channels. One of the channels had walls formed by $\mathrm{CF}_{3}$ substituents of ligands. The as-synthesized sample included guest $\mathrm{H}_{2} \mathrm{O}$ molecules in the other hydrophilic channels but the desolvated form selectively took in hydrophobic heptane guests within its $\mathrm{CF}_{3}$-decorated channels. Ghosh and colleagues ${ }^{14}$ found that the desolvated form of the two-dimensional MOF, $\left\{\left[\mathrm{Cu}_{4}(\mathrm{~L} 3)_{4}(\mathrm{DMF})_{4}\right]\right.$ -3DMF\} $\left(\mathrm{H}_{2} \mathrm{~L} 3\right.$ is shown in Figure $\left.3 \mathrm{~g}\right)$, exhibited excellent water- 
a

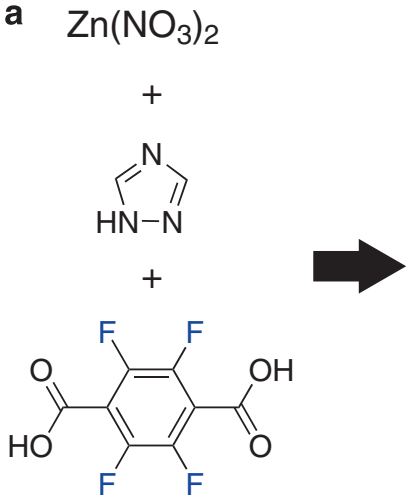

b

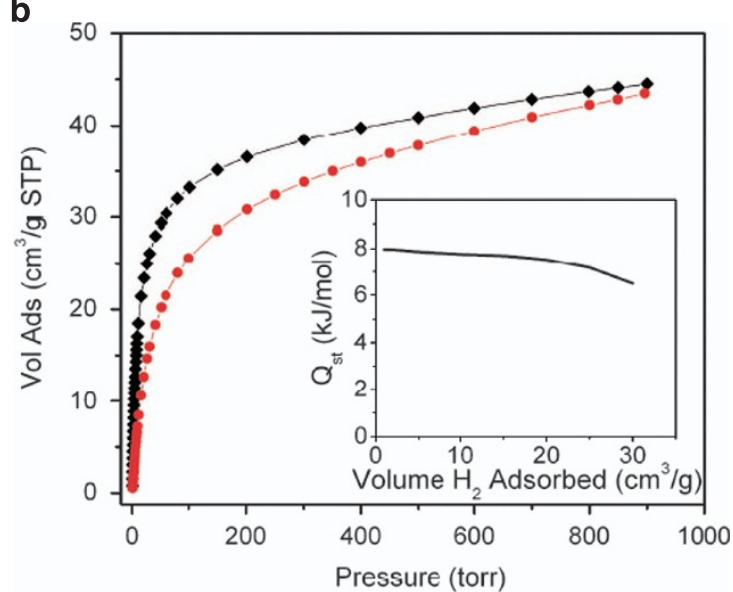

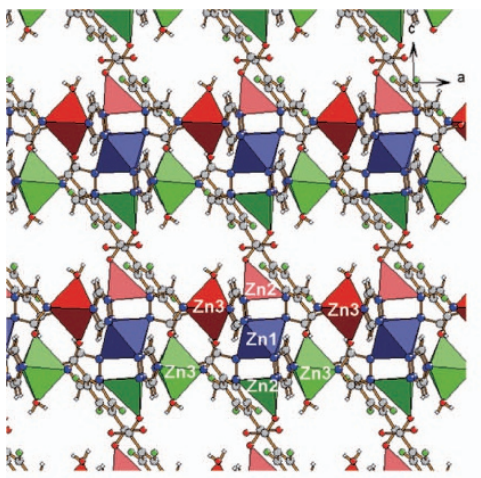

C

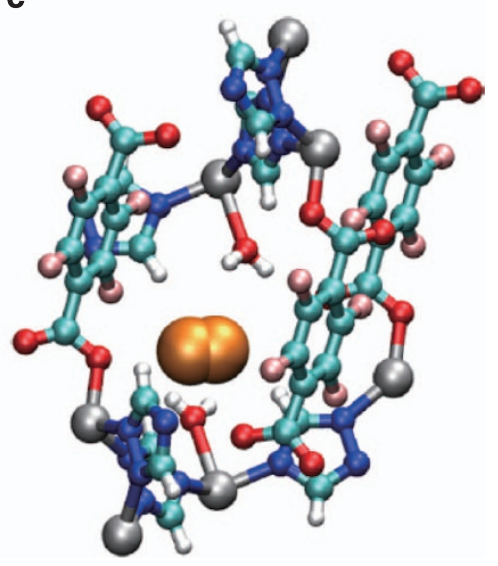

Figure 4 (a) Crystal structure of $\left.\left.\left\{\left[\mathrm{Zn}_{5} \text { (triazole }\right)_{6} \text { (tetrafluoroterephthalate }\right)_{2}\left(\mathrm{H}_{2} \mathrm{O}\right)_{2}\right] \cdot 4 \mathrm{H}_{2} \mathrm{O}\right\}$ viewed down the $b$ axis. Guest $\mathrm{H}_{2} \mathrm{O}$ molecules are omitted to show one-dimensional pores down the $b$ axis. (b) $\mathrm{H}_{2}$ adsorption isotherms at $77 \mathrm{~K}$ (black) and $87 \mathrm{~K}$ (red), and $Q_{\text {st }}$ plot. Reproduced from Hulvey et al. ${ }^{9}$ (c) Depiction of an adsorbed $\mathrm{H}_{2}$ molecule (orange) on the most favorable adsorption site as determined from simulation. Carbon atoms are depicted in cyan, hydrogen in white, nitrogen in blue, oxygen in red, fluorine in pink and zinc in silver. Reproduced from Forrest et al. ${ }^{10}$

repellent and oil/water separation properties derived from $\mathrm{CF}_{3}$ substituents on the L3 ligand. The fluorinated MOF, $\left[\mathrm{Ag}_{6}(\mathrm{tz})_{6}\right]$ ( $\mathrm{tz}=3,5$-bis(trifluoromethyl)-1,2,4-triazolate, Figure $3 \mathrm{~h}$ ), reported by Omary and colleagues, ${ }^{49}$ showed the three-dimensional porous framework consisting of tetranuclear $\left[\mathrm{Ag}_{4}(\mathrm{tz})_{6}\right]$ clusters connected by threecoordinate $\mathrm{Ag}(\mathrm{I})$ centers and had both large semi-rectangular channels $(\sim 12.2$ and $7.3 \AA)$ and small diamond-shaped cavities ( 6.6 and $4.9 \AA)$ coated with $\mathrm{CF}_{3}$ groups of the fluorinated tz ligands (Figure 5a). Because of its $\mathrm{CF}_{3}$-coated channels and cavities, this MOF adsorbed a negligible amount of water even under almost $100 \%$ relative humidity condition and retained its original porous structure after soaking in water for several days. ${ }^{15}$ In contrast, a high adsorption amount of C6-C8 hydrocarbons such as benzene, toluene, $p$-xylene, cyclohexane and $n$-hexane, the most common oil components, was observed (Figure 5b). Such hydrophobic character is effective in the field of oilspill clean-up. A hydrophobic space derived from fluorine atoms was also suitable for investigating properties of water clusters themselves due to the negligible interaction of water molecules with the pore walls. Omary and colleagues ${ }^{16}$ reported water cluster confinement in the hydrophobic cavities using the same fluorinated MOF, $\left[\mathrm{Ag}_{6}(\mathrm{tz})_{6}\right]$. From Raman and IR spectroscopy and theoretical calculations, it was suggested that a small number of pentamer water clusters were formed in the large pores and the binding energy between the water clusters and the $\mathrm{CF}_{3}$-decorated walls was weak.
A hydrophobic nature of fluorine-containing materials contributes to a high stability to water. Senkovska and colleagues ${ }^{17}$ succeeded in the incorporation of the hydrophobic fluorinated monocarboxylate ligands such as trifluoroacetate, 4-(trifluoromethyl)benzoate and pentafluorobenzoate (Figure $3 \mathrm{i}-\mathrm{k}$, respectively) to the threedimensional $\mathrm{Zr}$ MOF of $\left[\mathrm{Zr}_{6} \mathrm{O}_{6}(\mathrm{OH})_{2}(\mathrm{tdc})_{4}(\mathrm{HCOO})_{2}\right]$ (DUT-67-Fa, $\mathrm{H}_{2} \mathrm{tdc}=2,5$-thiophenedicarboxylic acid) using the solvent-assisted ligand incorporation technique. ${ }^{45}$ The exchange of $\mathrm{HCOO}^{-}$for these fluorinated monocarboxylates was performed by immersing the parent DUT-67-Fa in a DMF solution of the respective carboxylic acid. The tolerance of the obtained carboxylate-exchanged materials toward the removal of adsorbed water could be significantly enhanced compared with the parent DUT-67-Fa MOF.

\section{MOFS FUNCTIONALIZED WITH INORGANIC FLUORINATED ANIONS}

Inorganic fluorinated anions as illustrated in Figure 6 are also good building blocks for the construction of fluorine-functionalized MOFs/PCPs. $\mathrm{AF}_{6}{ }^{2-}$ anions $(\mathrm{A}=\mathrm{Si}, \mathrm{Ge}, \mathrm{Sn}$ and $\mathrm{Ti})$ can be used as bridging ligands for MOFs due to their high density of negative charge on fluorine atoms. ${ }^{18-27,29,50}$ There are many $\mathrm{AF}_{6}{ }^{2-}$-bridged MOFs, $\left[\mathrm{M}\left(\mathrm{AF}_{6}\right)(\mathrm{L})_{2}\right]$, in which $\mathrm{M}$ is $\mathrm{Fe}(\mathrm{II}), \mathrm{Co}(\mathrm{II}), \mathrm{Ni}(\mathrm{II}), \mathrm{Cu}(\mathrm{II})$ or $\mathrm{Zn}(\mathrm{II})$ cations, and $\mathrm{L}$ is pyrazine (pyz) or bipyridine-type neutral ligands, and their prototypes are $\left[\mathrm{M}\left(\mathrm{SiF}_{6}\right)\left(4,4^{\prime} \text {-bpy }\right)_{2}\right]\left(\mathrm{M}=\mathrm{Zn}(\mathrm{II})\right.$ or $\mathrm{Cu}(\mathrm{II}), 4,4^{\prime}$ bpy $=4,4^{\prime}$-bipyridine), which form the three-dimensional porous 

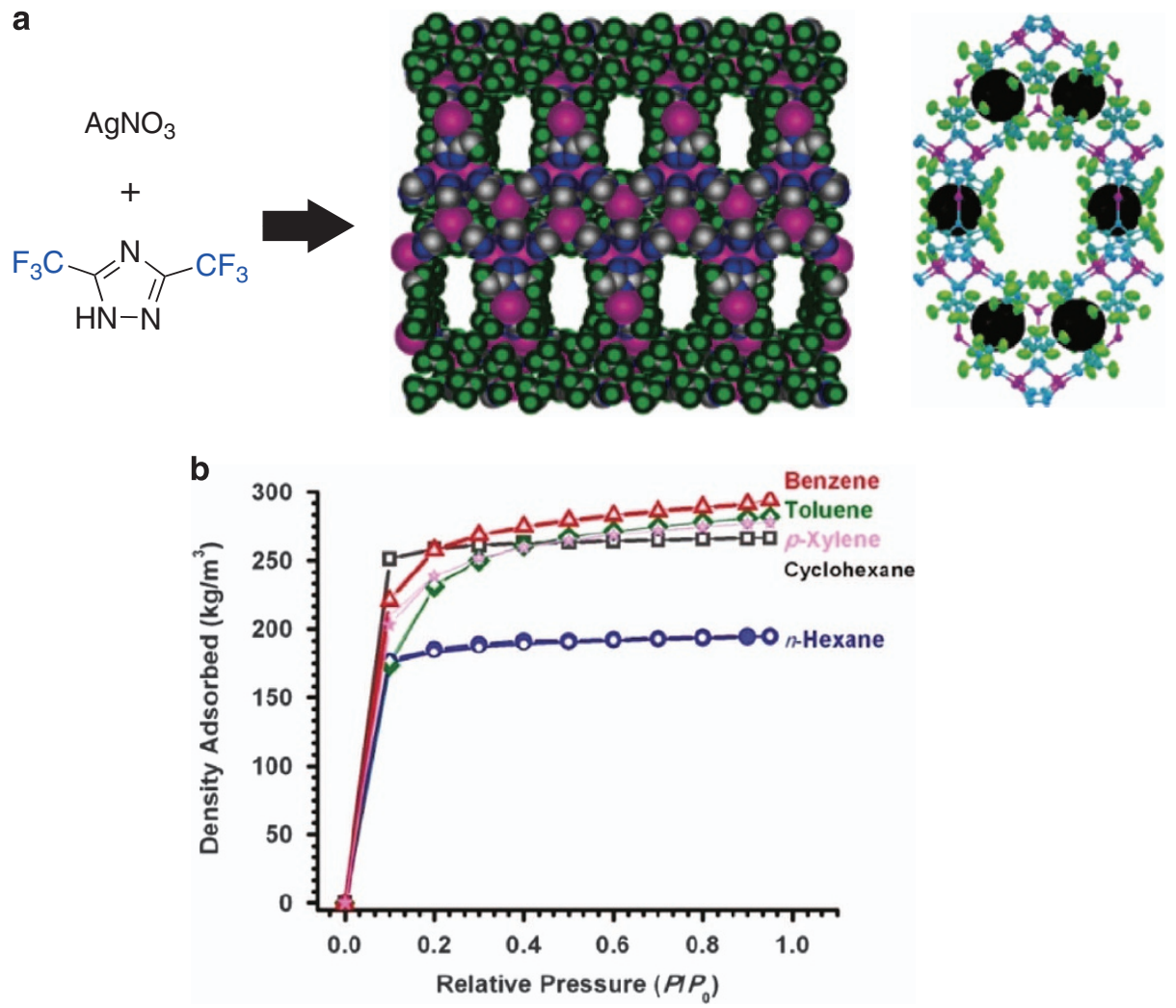

Figure 5 (a) Crystal structure of $\left[\mathrm{Ag}_{6}(\mathrm{tz})_{6}\right]$. In the right figure, the small cavities are denoted by black circles that surround the large channels. (b) Adsorption/ desorption isotherms for benzene, toluene, $p$-xylene, cyclohexane and $n$-hexane. Closed and open symbols indicate adsorption and desorption, respectively. Reproduced from Yang et al. ${ }^{15,49}$

$$
\left[\mathrm{F}_{\mathrm{F}}^{\mathrm{F}} \mathrm{A}^{\mathrm{A}}-\mathrm{F}\right]^{2-}
$$<smiles></smiles><smiles>CCCCCCCP(F)(F)(F)F</smiles>

$\mathrm{A}=\mathrm{Si}, \mathrm{Ge}, \mathrm{Sn}$, and $\mathrm{Ti}$<smiles>CCP(C)(F)(F)F</smiles><smiles>O=S(=O)([O-])C(F)(F)F</smiles><smiles>O=S(=O)([O-])N=S(=O)([O-])C(F)(F)F</smiles>

Figure 6 Inorganic fluorinated building units.

primitive cubic structure constructed from two-dimensional $\left[\mathrm{M}\left(4,4^{\prime}-\right.\right.$ bpy $\left.)_{2}\right]_{n}$ sheets and inorganic $\mathrm{SiF}_{6}{ }^{2-}$ pillars. ${ }^{18,19}$ The $\mathrm{Cu}(\mathrm{II})$ compound, $\left[\mathrm{Cu}\left(\mathrm{SiF}_{6}\right)\left(4,4^{\prime} \text {-bpy) }\right)_{2}\right.$ (SIFSIX-1-Cu), was shown to have permanent pores and exhibit a high uptake of $\mathrm{CH}_{4}\left(6.5 \mathrm{mmol} \mathrm{g}^{-1}\right.$ at $298 \mathrm{~K}$ and $36 \mathrm{~atm}$ ) and selective $\mathrm{CO}_{2}$ uptake over $\mathrm{CH}_{4}$ (10.5 (IAST $\mathrm{CO}_{2} / \mathrm{CH}_{4}(50: 50)$ selectivity) at $298 \mathrm{~K}$ and $1 \mathrm{~atm}$ ), and selective $\mathrm{C}_{2} \mathrm{H}_{2}$ uptake over $\mathrm{C}_{2} \mathrm{H}_{4}\left(8.37\right.$ (IAST $\mathrm{C}_{2} \mathrm{H}_{2} / \mathrm{C}_{2} \mathrm{H}_{4}(50: 50)$ selectivity) at $298 \mathrm{~K}$ and $1 \mathrm{~atm}) .{ }^{19-21}$ In general, this type of MOF with $\mathrm{Co}(\mathrm{II}), \mathrm{Ni}(\mathrm{II})$ and $\mathrm{Zn}(\mathrm{II})$ is obtained in non-aqueous condition because $\mathrm{H}_{2} \mathrm{O}$ is preferentially coordinated to these metal centers instead of the weak Lewis base $\mathrm{SiF}_{6}{ }^{2-}\left(\mathrm{p} K_{\mathrm{a}}=1.92\right){ }^{21}$ In contrast, the $\mathrm{Cu}$ types can be prepared even in the presence of $\mathrm{H}_{2} \mathrm{O}$. $\mathrm{Cu}(\mathrm{II})$ complexes have longer axial coordination bonds than equatorial bonds because of a JahnTeller effect and, therefore, there is a relatively large contribution of electrostatic interaction to the axial coordination bonds, which enables the preferential coordination of $\mathrm{SiF}_{6}{ }^{2-}$ dianion to the $\mathrm{Cu}(\mathrm{II})$ axial site compared with a neutral $\mathrm{H}_{2} \mathrm{O}$ molecule. Use of the $\mathrm{Cu}(\mathrm{II})$ axial sites permitted even a stable bridge of metal centers by an inorganic fluorinated $\mathrm{PF}_{6}{ }^{-}$monoanion. We succeeded in the synthesis of the three-dimensional MOF, $\left\{\left[\mathrm{Cu}_{2}\left(\mathrm{PF}_{6}\right)\left(\mathrm{NO}_{3}\right)\left(4,4^{\prime} \text {-bpy }\right)_{4}\right] \cdot 2 \mathrm{PF}_{6}\right\}$, in which the $\mathrm{PF}_{6}{ }^{-}$and $\mathrm{NO}_{3}{ }^{-}$anions alternately bridged the $\mathrm{Cu}(\mathrm{II})$ axial sites of adjacent two-dimensional layers with $\mathrm{Cu}-\mathrm{F}$ and $\mathrm{Cu}-\mathrm{O}$ distances of 2.676(4) and 2.320(5) $\AA$, respectively (Figure 7a). ${ }^{25}$ In fact, this MOF was stable after the removal of guest molecules and the desolvated form showed a type I adsorption isotherm for $\mathrm{N}_{2}$ at $77 \mathrm{~K}$ with a Brunauer-Emmett-Teller specific surface area of $559 \mathrm{~m}^{2} \mathrm{~g}^{-1}$, suggesting the presence of stable micropores (Figure $7 \mathrm{~b}$ ). The $\mathrm{SiF}_{6}{ }^{2-}$ pillars had an important role in the formation of favorable MOFsorbate interactions via non-coordinated $\mathrm{F}$ atoms, which was confirmed using modeling studies, and X-ray and neutron diffraction analysis. ${ }^{21,23,26}$ The exceptional $\mathrm{CO}_{2}$ separation ability of the threedimensional MOF, $\left[\mathrm{Zn}\left(\mathrm{SiF}_{6}\right)\left(\mathrm{pyz}_{2}\right] \quad(\mathrm{SIFSIX}-3-\mathrm{Zn}\right.$, pyz = pyrazine), was reported by Nugent et al. ${ }^{23}$ in which the modeling studies revealed close interactions between electropositive carbon atoms of $\mathrm{CO}_{2}$ molecules and four negatively charged fluorine atoms of $\mathrm{SiF}_{6}{ }^{2-}$ pillars. Xing and colleagues ${ }^{21}$ crystallographically characterized the $\mathrm{C}_{2} \mathrm{D}_{2}$-adsorbed structure of SIFSIX-1-Cu using the powder neutron diffraction technique. $\mathrm{C}-\mathrm{D} \bullet \bullet \mathrm{F}$ hydrogen bonds $(2.063 \AA)$ were observed between $\mathrm{C}_{2} \mathrm{D}_{2}$ and $\mathrm{SiF}_{6}{ }^{2-}$ dianions, and the other $\mathrm{D}$ interacted with a neighboring $\mathrm{C}_{2} \mathrm{D}_{2}$ molecule with $\mathrm{C}-\mathrm{D} \cdot \bullet^{\circ} \mathrm{C}$ distances of 3.063 and $3.128 \AA$, which synergistically contributed to high selective $\mathrm{C}_{2} \mathrm{H}_{2}$ separation from a $\mathrm{C}_{2} \mathrm{H}_{2} / \mathrm{C}_{2} \mathrm{H}_{4}$ mixture (Figure 8). Space and colleagues ${ }^{28}$ recently found that the $\mathrm{SiF}_{6}{ }^{2-}$ anion connected other type of cationic two-dimensional sheets, $\left[\mathrm{Cu}_{3}(4\right.$-(pyridin-4-yl) acrylate) $]$, to form the neutral three-dimensional $\left[\mathrm{Cu}_{3}\right.$ (4-(pyridin-4- 
a
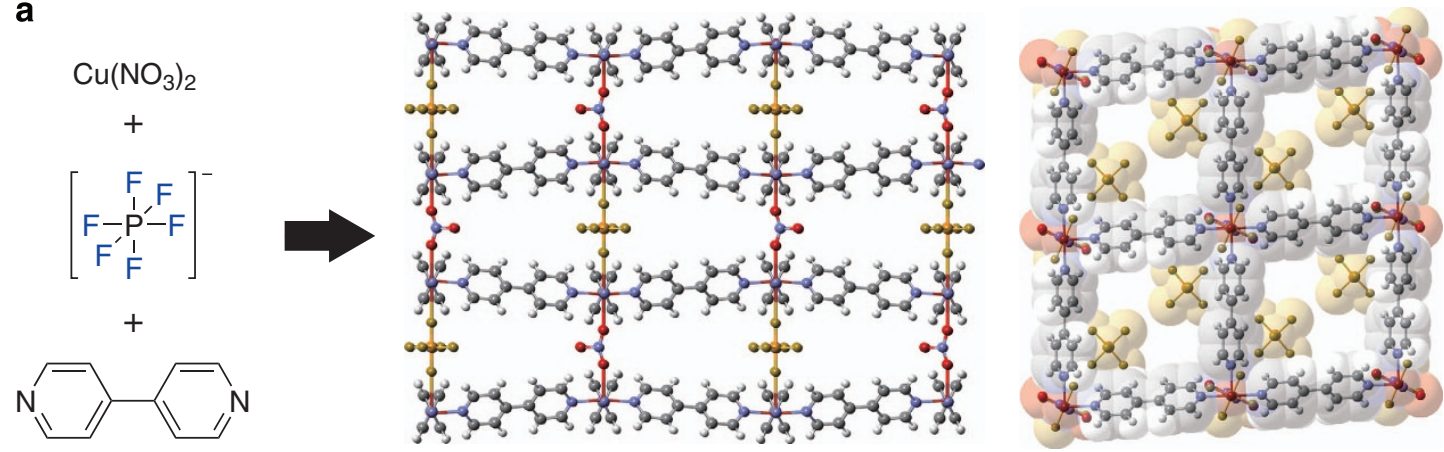

b

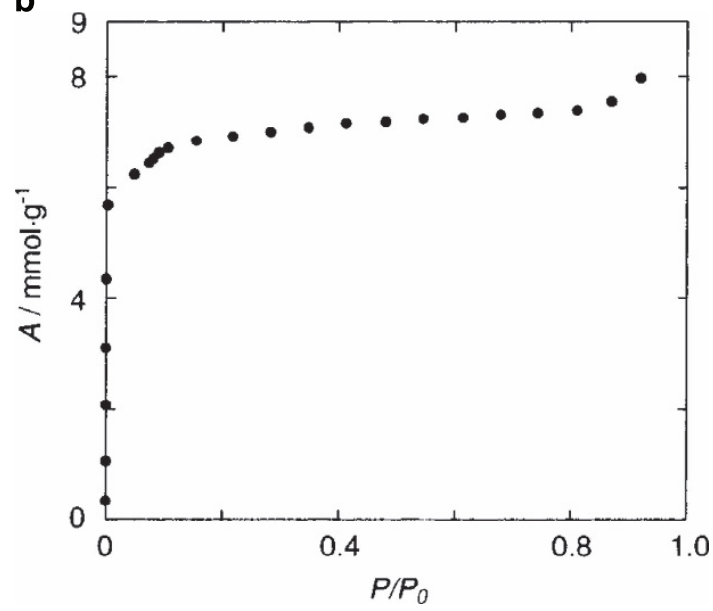

Figure 7 (a) Porous structure with bridged $\mathrm{PF}_{6}{ }^{-}$anions (the non-coordinated $\mathrm{PF}_{6}{ }^{-}$anions are omitted for clarity in the central figure) and (b) $\mathrm{N}_{2}$ adsorption isotherms at $77 \mathrm{~K}$ in $\left\{\left[\mathrm{Cu}_{2}\left(\mathrm{PF}_{6}\right)\left(\mathrm{NO}_{3}\right)\left(4,4^{\prime}-\mathrm{bpy}\right)_{4}\right] \cdot 2 \mathrm{PF}_{6}\right\}$. Reproduced from Noro et al. ${ }^{25}$

yl)acrylate) $\left.\left(\mathrm{SiF}_{6}\right)\right]$ (fsc-2-SIFSIX) with both coordinatively unsaturated $\mathrm{Cu}(\mathrm{II})$ and $\mathrm{SiF}_{6}$ fluorine sites for a $\mathrm{CO}_{2}$ gas trapping. Computational studies revealed that a primary $\mathrm{CO}_{2}$ adsorption site was the two $\mathrm{Cu}$ (II) cations of adjacent paddle-wheel $\left[\mathrm{Cu}_{2}\left(\mathrm{CO}_{2} \mathrm{R}\right)_{4}\right]$ moieties and a secondary adsorption site was the two equatorial $\mathrm{SiF}_{6}{ }^{2-}$ fluorine atoms.

In contrast to the organic fluorinated ligands, it is very difficult to modify inorganic fluorinated ligands at will. However, Eddaoudi and colleagues $^{29,30}$ succeeded in the preparation of a fine-tuned fluorinated MOF by modification of the inorganic fluorinated anions. They used a $\mathrm{NbOF}_{5}{ }^{2-}$ dianion instead of $\mathrm{SiF}_{6}{ }^{2-}$ to afford the three-dimensional MOF, $\left[\mathrm{Ni}\left(\mathrm{NbOF}_{5}\right)(\mathrm{pyz})_{2}\right]$. Because of its longer $\mathrm{Nb}-\mathrm{F}$ bond length (1.899(1) $\AA$ ) than the Si-F bond (1.681(1) $\AA$ ) and greater Lewis basicity, this MOF provided an appropriate pore space for capturing trace $\mathrm{CO}_{2}$, separating propylene form propane and enhanced water stability.

Inorganic fluorinated monoanions such as $\mathrm{PF}_{6}{ }^{-}, \mathrm{BF}_{4}{ }^{-}, \mathrm{CF}_{3} \mathrm{SO}_{3}{ }^{-}$and $\left(\mathrm{CF}_{3} \mathrm{SO}_{2}\right)_{2} \mathrm{~N}^{-}$have been used as counter anions of ionic liquids. ${ }^{51}$ As the negative charge of these anions is delocalized by fluorine atoms, electrostatic interaction between these anions and cations is weaker than that between non-fluorinated anions and cations, which causes low melting points. The same situation, that is, weaker intermolecular interactions, should be observed between fluorinated anions and neutral molecules. In addition, the poor metal-bridging ability of these monoanions contributes to the lowering of a framework dimensionality from three dimensions to two and one dimension. Therefore, the introduction of inorganic fluorinated monoanions to MOFs/PCPs may afford flexible materials showing gate-sorption/breathing behaviors.
The two-dimensional MOF $\left[\mathrm{Cu}\left(\mathrm{BF}_{4}\right)_{2}\left(4,4^{\prime} \text {-bpy }\right)_{2}\right]$ (ELM-11; ELM, elastic-layer-structured MOF) was the first flexible material with inorganic fluorinated anions. ${ }^{31}$ This $\mathrm{Cu}(\mathrm{II}) \mathrm{MOF}$, which was prepared by dehydration of the precursor one-dimensional coordination polymer $\left\{\left[\mathrm{Cu}\left(\mathrm{BF}_{4}\right)_{2}\left(4,4^{\prime}\right.\right.\right.$-bpy $\left.)\left(\mathrm{H}_{2} \mathrm{O}\right)_{2}\right] \bullet 4,4^{\prime}$-bpy $\},{ }^{52}$ had a two-dimensional square-grid framework with weakly coordinated $\mathrm{BF}_{4}^{-}$anions at the $\mathrm{Cu}$ (II) axial sites (Figure 9a) and showed gate-sorption behaviors for $\mathrm{CO}_{2}$ with interlayer expansion/shrinkage (Figure 9b). ${ }^{31,53}$ After this finding, the derivatives $\left[\mathrm{M}(\mathrm{A})_{2}\left(4,4^{\prime} \text {-bpy }\right)_{2}\right]\left(\mathrm{M}=\mathrm{Cu}, \mathrm{A}=\mathrm{CF}_{3} \mathrm{SO}_{3} ; \mathrm{M}=\mathrm{Cu}\right.$, $\mathrm{A}=\mathrm{PF}_{6} ; \mathrm{M}=\mathrm{Co}$ and $\mathrm{A}=\mathrm{CF}_{3} \mathrm{SO}_{3}$ ) were separately reported. ${ }^{32-34}$ These $\mathrm{MOF}$ formed similar two-dimensional square-grid frameworks with weakly coordinated $\mathrm{CF}_{3} \mathrm{SO}_{3}{ }^{-}$and $\mathrm{PF}_{6}{ }^{-}(\mathrm{Cu})$, and coordinated $\mathrm{CF}_{3} \mathrm{SO}_{3}{ }^{-}$ (Co) monoanions but showed different sorption behaviors from the parent ELM-11; there were two sorption events: the first uptake was a micropore filling and the second uptake was caused by a gate-sorption process with an expansion of the interlayer distance and sliding between the layers. Using these anions, it is also possible to fabricate one-dimensional flexible MOFs exhibiting gate sorption. ${ }^{35-40,54} \mathrm{We}$ reported the one-dimensional flexible $\left.\mathrm{MOF},\left[\mathrm{Cu}\left(\mathrm{PF}_{6}\right)_{2} \text { (bpetha }\right)_{2}\right]$ (bpetha $=1,2$-bis(4-pyridyl)ethane). ${ }^{35,36,54}$ This MOF exhibited doubly linked one-dimensional chain structures consisting of $\mathrm{Cu}(\mathrm{II})$ ions and bent bpetha ligands with weakly coordinated $\mathrm{PF}_{6}{ }^{-}$monoanions at its axial sites. $\mathrm{CO}_{2}$ and $\mathrm{C}_{2} \mathrm{H}_{2}$ gases were selectively adsorbed to this MOF with structural changes. ${ }^{35}$ The coordination state of the $\mathrm{PF}_{6}{ }^{-}$monoanions was retained during the change in structures and the adsorbed $\mathrm{CO}_{2}$ gas may interact with the fluorine atoms of weakly coordinated $\mathrm{PF}_{6}{ }^{-}$monoanions. This $\mathrm{MOF}$ also showed selective uptake of a larger 2-butanone guest from 2-butanone/EtOH and 2-butanone/MeOH 
mixtures. ${ }^{36}$ The 2-butanone guest with an $\mathrm{sp}^{2}$ coordinated oxygen atom could coordinate to the $\mathrm{Cu}(\mathrm{II})$ axial sites instead of the $\mathrm{PF}_{6}{ }^{-}$ monoanion, whereas the $\mathrm{EtOH}$ and $\mathrm{MeOH}$ guests with a sterically crowded $s p^{3}$ coordinated oxygen atom were hard to coordinate to the sterically crowded $\mathrm{Cu}(\mathrm{II})$ axial sites that are formed by the coordination

a
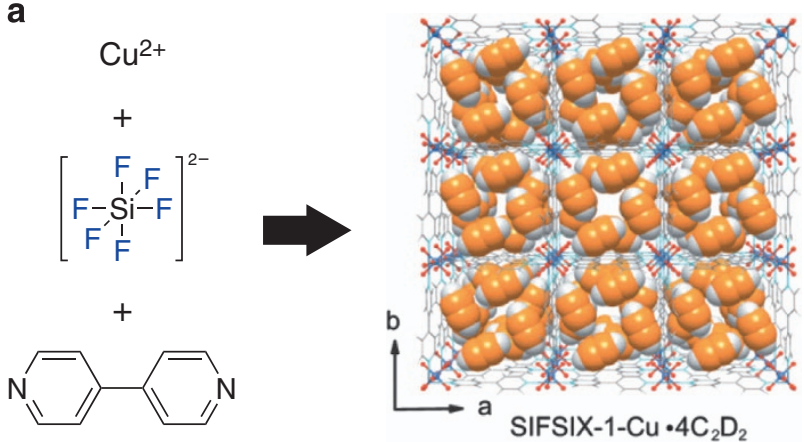

b

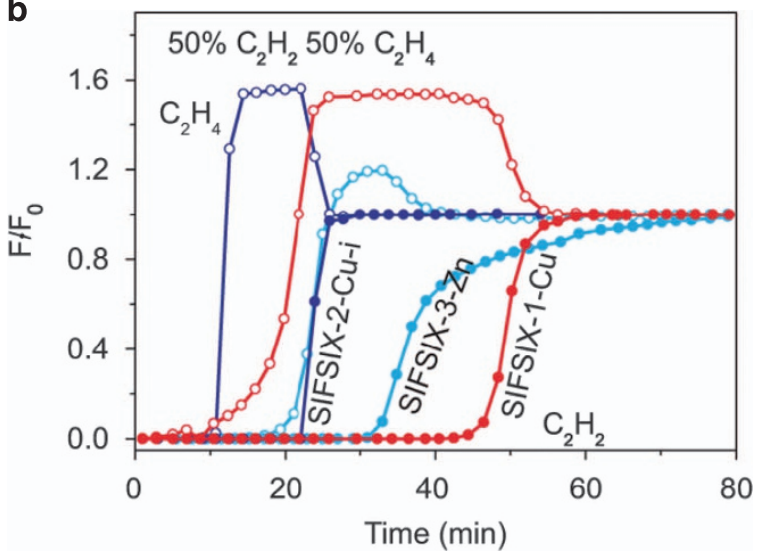

Figure 8 (a) Crystal structure and (b) experimental column breakthrough curves for $\mathrm{C}_{2} \mathrm{H}_{2} / \mathrm{C}_{2} \mathrm{H}_{4}$ (50:50) separation at $298 \mathrm{~K}$ and $1 \mathrm{~atm}$ in $\left[\mathrm{Cu}\left(\mathrm{SiF}_{6}\right)\right.$ $\left(4,4^{\prime} \text {-bpy }\right)_{2}$ ] (SIFSIX-1-Cu). SIFSIX-2-Cu-i is $\left[\mathrm{Cu}\left(\mathrm{SiF}_{6}\right)\left(4,4^{\prime} \text {-dipyridylacetylene }\right)_{2}\right]$ $\left(\mathrm{i}=\right.$ interpenetrated). Reproduced from Cui et al. ${ }^{21}$ of four bpetha pyridine moieties from the equatorial direction, which was the origin of the high selectivity for the larger 2-butanone guest.

Ionic liquids with inorganic fluorinated monoanions have been found to adsorb $\mathrm{CO}_{2}$ gas selectively over other gases through $\mathrm{F} \cdot \bullet \mathrm{CO}_{2}$ interactions. In some MOFs with inorganic fluorinated monoanions, selective $\mathrm{CO}_{2}$ adsorption and separation were observed. ${ }^{33,37,39} \mathrm{We}$ reported selective $\mathrm{CO}_{2}$ adsorption over $\mathrm{CH}_{4}$ in the one-dimensional MOF, $\left[\mathrm{Cu}\left(\mathrm{PF}_{6}\right)_{2}(\mathrm{bpp})_{2}\right] \quad\left(\mathrm{bpp}=1,3\right.$-bis(4-pyridyl)propane). ${ }^{39}$ The bent bpp ligands and the $\mathrm{Cu}(\mathrm{II})$ ions formed a doubly linked chain with weakly coordinated $\mathrm{PF}_{6}{ }^{-}$anions at the axial sites (Figure 10a). At $298 \mathrm{~K}$, this $\mathrm{MOF}$ adsorbed $\mathrm{CO}_{2}$ gas but $\mathrm{CH}_{4}$ and $\mathrm{H}_{2} \mathrm{O}$ were hardly adsorbed (Figure 10b), suggesting an availability for separation of the $\mathrm{CO}_{2} / \mathrm{CH}_{4}$ mixture under dry and even humid conditions. In fact, it was experimentally proven that this MOF showed high equilibrium and kinetic separation for $\mathrm{CO}_{2}$ over $\mathrm{CH}_{4}$ under realistic conditions, using a mixed gas at room temperature and in a humid environment (Figure $10 \mathrm{~b}$ and $\mathrm{c}$ ). The moderate heat of $\mathrm{CO}_{2}$ adsorption $\left(Q_{\mathrm{st}}=-18\right.$ to $\left.-31 \mathrm{~kJ} \mathrm{~mol}^{-1}\right)$, which was experimentally determined, and the calculated interaction energy using a model structure (Figure 10d) ${ }^{32}$ suggested that the fluorine atoms of the weakly coordinated $\mathrm{PF}_{6}{ }^{-}$anions contribute to the interaction sites with adsorbed $\mathrm{CO}_{2}$ molecules. To elucidate the interactions between inorganic fluorinated monoanions and guest molecules in detail, it is important to determine the crystal structures with adsorbed guest molecules. Recently, the $\mathrm{CO}_{2}$-adsorbed structures of ELM-11 and onedimensional MOF $\left[\mathrm{Cu}\left(\mathrm{BF}_{4}\right)_{2}(\mathrm{bpp})_{2}\right]^{38}$ showing $\mathrm{CO}_{2}$ gate sorption were successfully determined from synchrotron powder X-ray diffraction data. ${ }^{55,56}$ In the $\mathrm{CO}_{2}$-adsorbed ELM-11 (ELM-11 $\supset 2 \mathrm{CO}_{2}$ ), one $\mathrm{CO}_{2}$ interacted with two neighboring $\mathrm{BF}_{4}{ }^{-}$anions with $\mathrm{F} \bullet \bullet \mathrm{C}$ distances of 2.918 and $2.932 \AA,{ }^{55}$ whereas the $\mathrm{CO}_{2}$-adsorbed one-dimensional MOF, $\left\{\left[\mathrm{Cu}\left(\mathrm{BF}_{4}\right)_{2}(\mathrm{bpp})_{2}\right] \bullet 0.7 \mathrm{CO}_{2}\right\}$, formed $\mathrm{F} \bullet \bullet \mathrm{CO}_{2}$ interactions $\left(\mathrm{F} \bullet \bullet \mathrm{C}=2.61(6) \AA\right.$, see Figure 11a). ${ }^{56}$ If single crystals of MOFs with inorganic fluorinated monoanions have permanent micropores and retain their single crystallinity after removal of guest molecules, they could be available for determining guest-adsorbed structures and discussing interactions between inorganic fluorinated monoanions and guest molecules by single-crystal X-ray diffraction measurements. However, such permanent single crystals are difficult to synthesize,

a
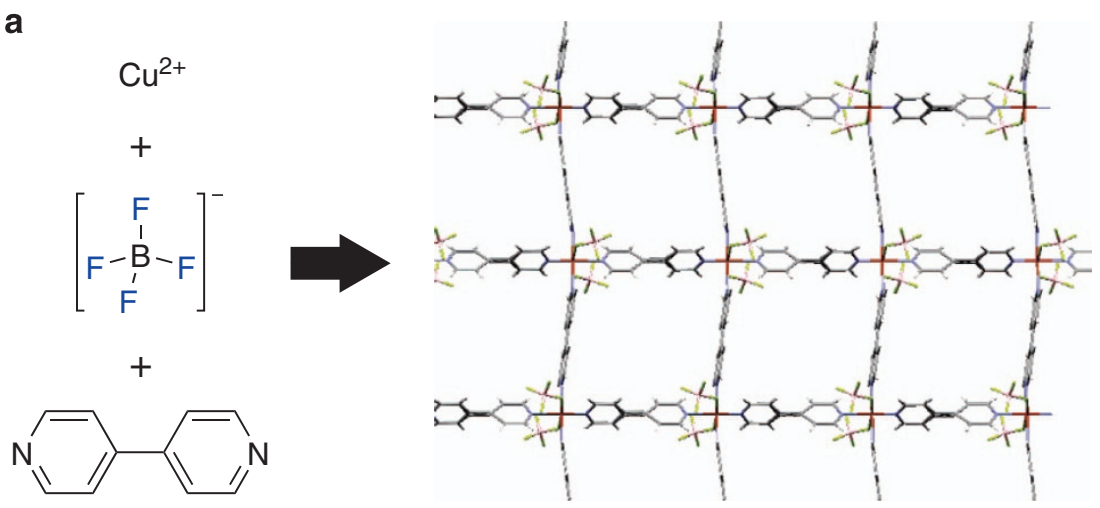

b

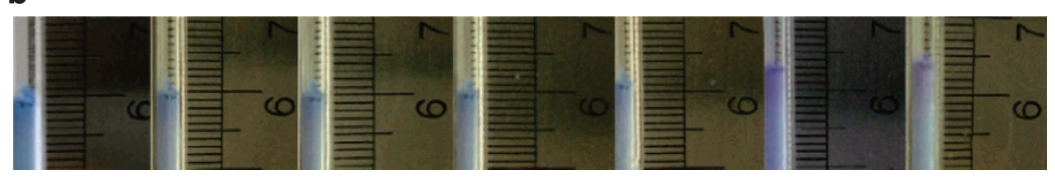

Figure 9 (a) Two-dimensional structure and (b) change in the sample volume on increasing $\mathrm{CO}_{2}$ pressure (from the left, $0,6.66,13.3,26.7,34.7,45.3$ and $101 \mathrm{kPa})$ at $273 \mathrm{~K}$ in $\left[\mathrm{Cu}\left(\mathrm{BF}_{4}\right)_{2}\left(4,4^{\prime}-\mathrm{bpy}\right)_{2}\right]$. Reproduced from Kondo et al. ${ }^{31}$ 
a

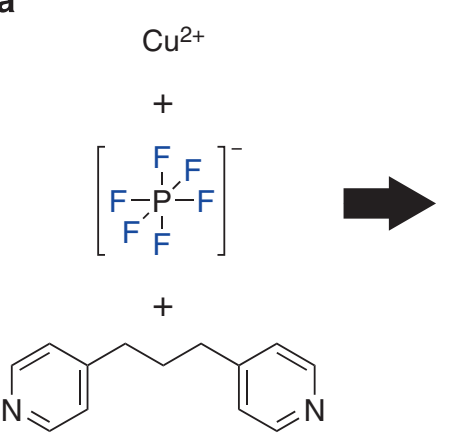

b

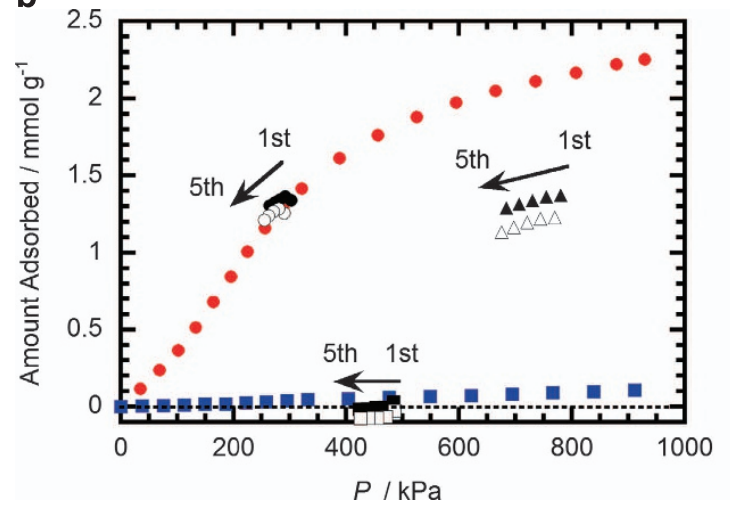

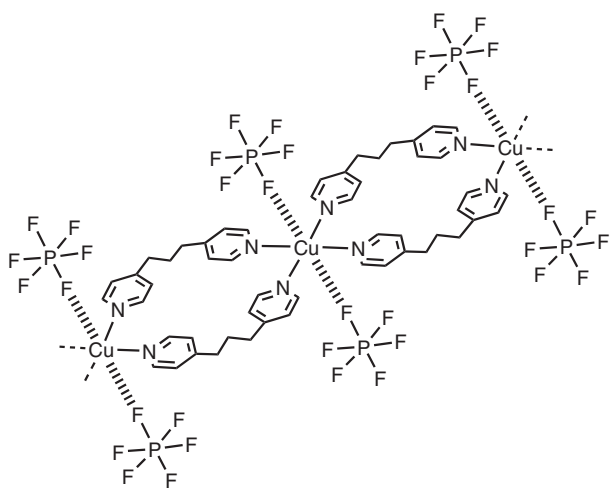

C

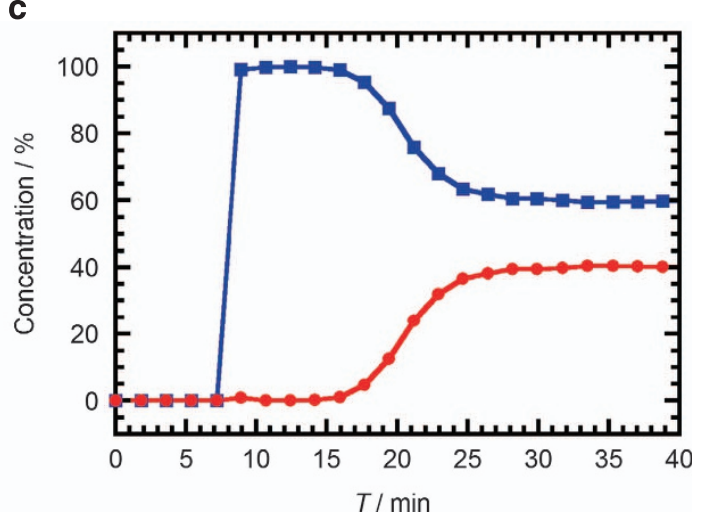

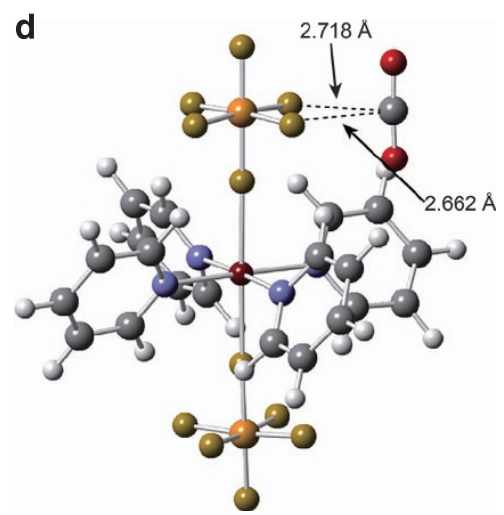

Figure 10 Structure and gas separation properties of $\left[\mathrm{Cu}\left(\mathrm{PF}_{6}\right)_{2}(\mathrm{bpp})_{2}\right]$. (a) Schematic view of the structure. (b) Single-gas and mixed-gas equilibrium adsorption properties at $298 \mathrm{~K}$ under dry and humid conditions. The single-gas adsorption isotherms for $\mathrm{CO}_{2}$ and $\mathrm{CH}_{4}$ are shown in filled red circles and blue squares, respectively. The open black circles, squares and triangles indicate the $\mathrm{CO}_{2}, \mathrm{CH}_{4}$ and total adsorption amounts, respectively, for the mixed gas of $\mathrm{CO}_{2}: \mathrm{CH}_{4}=40: 60$ (mol). The filled black symbols correspond to their adsorption amounts for the mixed gas of $\mathrm{CO}_{2}: \mathrm{CH}_{4}: \mathrm{H}_{2} \mathrm{O}=39.98: 59.96: 0.06$ (mol), in which each adsorption amount is calculated according to the hypothesis that water is hardly adsorbed at all. The mixed-gas adsorption measurements were repeated five times. (c) Breakthrough curves of $\mathrm{CO}_{2} / \mathrm{CH}_{4}$ mixture (measurement condition: $\mathrm{CO}_{2}: \mathrm{CH}_{4}=40: 60$ (mol), the measurement temperature $=298 \mathrm{~K}$, the total pressure $=800 \mathrm{kPa}$ and the space velocity $=3 \mathrm{~min}^{-1}$ ). The red circles represent $\mathrm{CO}_{2}$ and the blue squares represent $\mathrm{CH}_{4}$. (d) Optimized structure of $\left.\left[\mathrm{Cu}\left(\mathrm{PF}_{6}\right)_{2} \text { (pyridine) }\right)_{4}\right]$ and $\mathrm{CO}_{2}$. Reproduced from Noro et al. 33,39

because the inorganic fluorinated monoanions often give flexible MOFs. We succeeded in the preparation of a stable single crystal of the two-dimensional MOF, $\left\{\left[\mathrm{Cu}\left(\mathrm{CF}_{3} \mathrm{SO}_{3}\right)(\mathrm{bpp})_{2}\right] \cdot \mathrm{PF}_{6}\right\}$, using an anionmixing method. ${ }^{41}$ Two coexistent types of inorganic fluorinated anions, $\mathrm{CF}_{3} \mathrm{SO}_{3}^{-}$and $\mathrm{PF}_{6}{ }^{-}$, with different Lewis basicities, enabled the formation of a higher dimensional, in this case two-dimensional, framework compared with the corresponding one-dimensional MOFs with only one type of anion, $\left[\mathrm{Cu}(\mathrm{A})_{2}(\mathrm{bpp})_{2}\right]\left(\mathrm{A}=\mathrm{CF}_{3} \mathrm{SO}_{3}\right.$ and $\left.\mathrm{PF}_{6}\right)$. In the acetone-including crystal $\left\{\left[\mathrm{Cu}\left(\mathrm{CF}_{3} \mathrm{SO}_{3}\right)(\mathrm{bpp})_{2}\right] \bullet \mathrm{PF}_{6} \bullet\right.$ acetone $\}$, the guest acetone molecules located in micropores formed weak hydrogen-bonding interactions with the bridged $\mathrm{CF}_{3} \mathrm{SO}_{3}{ }^{-}(\mathrm{C} \cdot \bullet \mathrm{O}=$
3.34(2) $\AA$ ) and non-coordinated $\mathrm{PF}_{6}{ }^{-}$anions $(\mathrm{C} \cdot \bullet \cdot \mathrm{F}=3.11(2) \AA)$, as shown in Figure 11b. After the removal of acetone guests, the single crystallinity was unchanged and we could determine the crystal structure of the completely desolvated form $\left\{\left[\mathrm{Cu}\left(\mathrm{CF}_{3} \mathrm{SO}_{3}\right)(\mathrm{bpp})_{2}\right]\right.$ $\left.-\mathrm{PF}_{6}\right\}$. As this $\mathrm{MOF}$ adsorbed $\mathrm{CO}_{2}$, a direct visualization of the interaction between fluorinated monoanions and adsorbed $\mathrm{CO}_{2}$ may be possible using a single-crystal X-ray diffraction technique.

Ionic liquids including inorganic fluorinated monoanions are good candidates as safe electrolytes in electrochemical devices because of their flame resistance, extremely low volatility, high thermal and electrochemical stability, and high ionic conductivity. However, their 

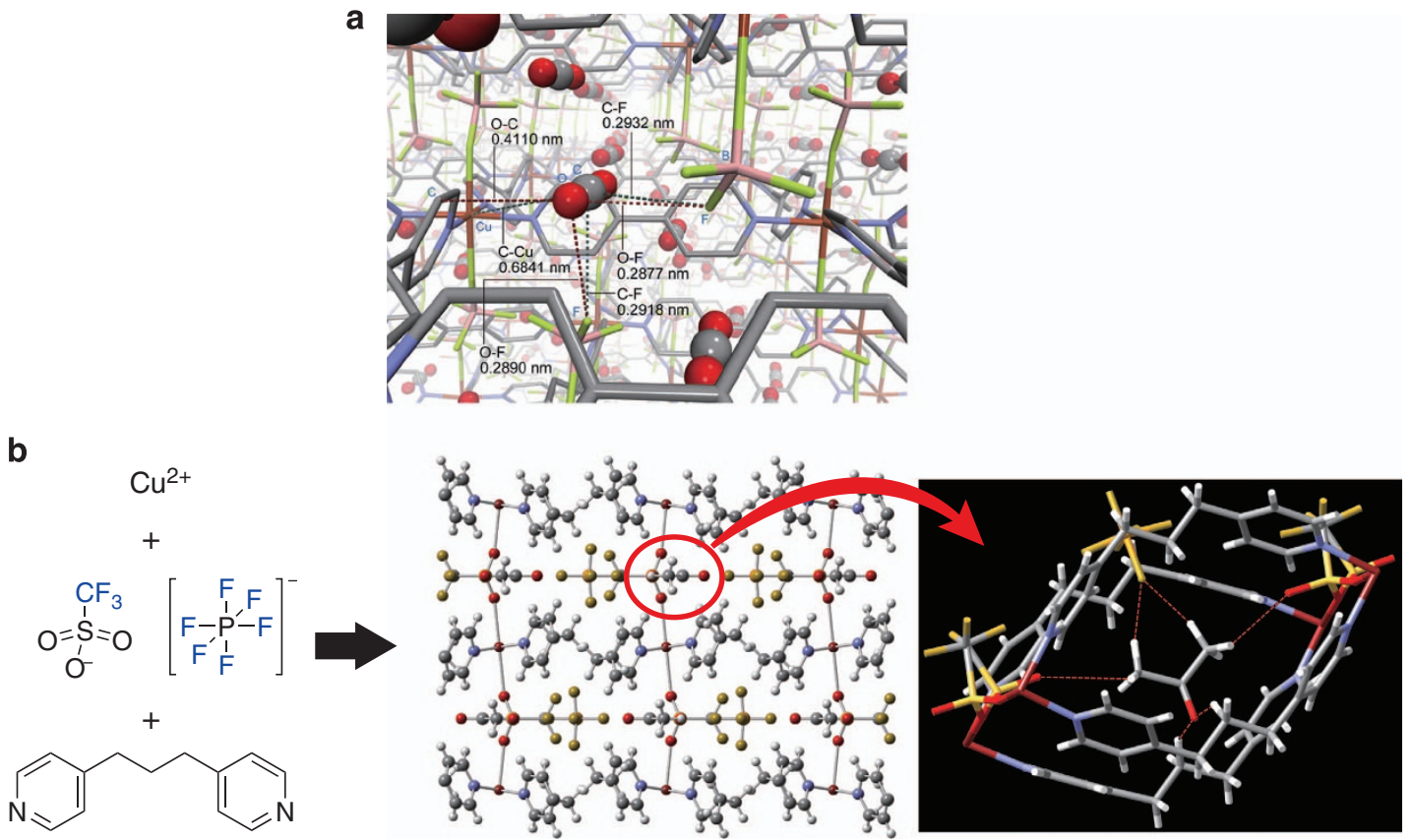

Figure 11 (a) $\mathrm{CO}_{2}$-adsorbed structure in $\left\{\left[\mathrm{Cu}\left(\mathrm{BF}_{4}\right)_{2}(\mathrm{bpp})_{2}\right] \cdot 2 \mathrm{CO}_{2}\right\}\left(\mathrm{ELM}-11 \supset 2 \mathrm{CO}_{2}\right)$. Reproduced from Tanaka et al. ${ }^{55}$ (b) Crystal structure and view of the interaction between the acetone guest and inorganic fluorinated $\mathrm{CF}_{3} \mathrm{SO}_{3}{ }^{-}$and $\mathrm{PF}_{6}{ }^{-}$anions in $\left\{\left[\mathrm{Cu}\left(\mathrm{CF}_{3} \mathrm{SO}_{3}\right)\left(\mathrm{bpp}_{2}\right] \cdot \mathrm{PF}_{6} \cdot\right.\right.$ acetone $\}$.

ionic conductivity dramatically decreases below their freezing points. Kitagawa and colleagues ${ }^{42}$ reported a low-temperature ionic conductor obtained by the incorporation of the ionic liquid, EMI-TSFA (1-ethyl3-methylimidazolium bis(trifluoromethylsulfonyl)amide) within the three-dimensional MOF, $\left[\mathrm{Zn}(\mathrm{MeIM})_{2}\right]$ (ZIF-8, HMeIM=2-methylimidazole). The ionic conductivity of EMI-TSFA@ZIF-8 was higher than that of bulk EMI-TFSA below $250 \mathrm{~K}$ because there is no freezing transition of the nanosized ionic liquid formed in the restricted pore space.

\section{PERFLUOROALKANE-FUNCTIONALIZED MOFS}

As is the case with previously introduced fluorine-containing MOF building units, perfluoroalkanes can provide polar adsorption sites. Furthermore, the assembly of these substituents is useful for the construction of a specific fluorophilic field and preferential adsorption field for $\mathrm{O}_{2}$ and $\mathrm{CO}_{2}$. There are two methods to adopt perfluoroalkyl substituents into MOFs; one is to use bridging ligands with their substituents and the other is the use of terminal ligands bearing them. The two-dimensional MOF, $\left\{\left[\mathrm{Co}(\mathrm{NCS})_{2}(\mathrm{~L} 4)_{2}\right] \bullet x\right.$ (guest) $\}$ (guest is ethylene glycol or $\mathrm{C}_{6} \mathrm{~F}_{14}$ and L4 is 1,3-bis(4-pyridylethynyl)-2$(3,3,4,4,5,5,6,6,7,7,8,8,8$-tridecafluorooctyloxy)benzene shown in Figure 12a), with the pendant perfluoroalkyl $\mathrm{C}_{6} \mathrm{~F}_{13}$ chains were synthesized by Fujita and colleagues. ${ }^{43}$ The stacking of the distorted two-dimensional grid frameworks created pores occupied by the $\mathrm{C}_{6} \mathrm{~F}_{13}$ chains and the guest molecules. When ethylene glycol guests (boiling point: $471 \mathrm{~K}$ ) were included, they started to be removed from the pores around $313 \mathrm{~K}$, similar to neat ethylene glycol. On the other hand, the clathrated perfluorohexane (boiling point: $329 \mathrm{~K}$ ) began to evaporate at around $268 \mathrm{~K}$, which was much higher than neat perfluorohexane $(\sim 223 \mathrm{~K})$, indicating high fluorophilicity and organophobicity. Matsuda and colleagues reported the densely perfluorobutyl-functionalized twodimensional MOF, $\{[\mathrm{Cu}(\mathrm{bpbtp})(\mathrm{L} 5)(\mathrm{DMF})] \bullet \mathrm{DMF}\} \quad\left(\mathrm{H}_{2}\right.$ bpbtp $=2,5-$ bis(perfluorobutyl)terephthalic acid, L5 =2,5-bis(perfluorobutyl)-1,4bis(4-pyridyl)benzene, Figure $12 \mathrm{~b}$ and $\mathrm{c}$ ), in which its pore surface was covered with perfluorobutyl substituents. The installation of a

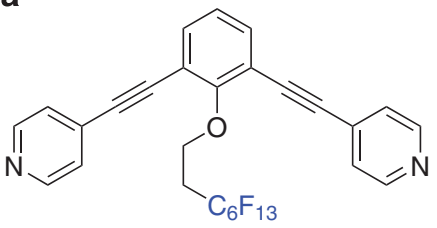

b<smiles>O=C(O)c1cc(C(F)(F)F)c(C(=O)O)cc1C(F)(F)F</smiles>

C<smiles>FC(F)(F)c1cc(-c2ccncc2)c(C(F)(F)F)cc1-c1ccncc1</smiles>

d

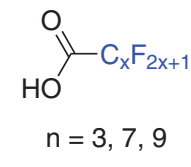

Figure 12 Structures of organic bridging and terminal ligands with perfluoroalkane substituents, (a) 1,3-bis(4-pyridylethynyl)-2-(3,3,4,4,5,5, 6,6,7,7,8,8,8-tridecafluorooctyloxy)benzene, (b) 2,5-bis(perfluorobutyl) terephthalic acid, (c) 2,5-bis(perfluorobutyl)-1,4-bis(4-pyridyl)benzene and (d) perfluoroalkanecarboxylic acid.

perfluorobutyl groups to both neutral and anionic bridging ligands enabled the formation of densely fluorinated pores (Figure 13a). The desolvated form of this MOF was found to show preferential adsorption for $\mathrm{CO}_{2}$ and $\mathrm{O}_{2}$ over $\mathrm{N}_{2}, \mathrm{Ar}$ and $\mathrm{CO}$ with hysteresis, which may be caused by the high dissolving ability of perfluoroalkanes for $\mathrm{CO}_{2}$ and $\mathrm{O}_{2}$. Using the solvent-assisted ligand incorporation technique, Snurr and colleagues ${ }^{45}$ succeeded in the incorporation of terminal perfluoroalkane carboxylate (Figure 12d) within the threedimensional $\mathrm{Zr}$-based MOF, $\left[\mathrm{Zr}_{6}\left(\mu_{3}-\mathrm{OH}\right)_{8}(\mathrm{OH})_{8}(\mathrm{TBAPy})_{2}\right]$ (NU-1000, $\mathrm{H}_{4}$ TBAPy $=1,3,6,8$-tetrakis ( $p$-benzoic acid)pyrene), as shown in Figure 13b. The octahedral $\mathrm{Zr}_{6}$ cluster has eight terminal $-\mathrm{OH}$ ligands, which can be exchanged with a variety of monocarboxylate ligands, including perfluoroalkane carboxylate, without destruction of the framework. Detailed sorption measurements and theoretical modeling confirmed that (1) the NU-1000 functionalized with a perfluoroalkane carboxylate exhibited a systematically higher value 
a

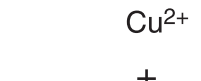<smiles>O=C(O)c1cc(C(F)(F)F)c(C(=O)O)cc1C(F)(F)F</smiles>

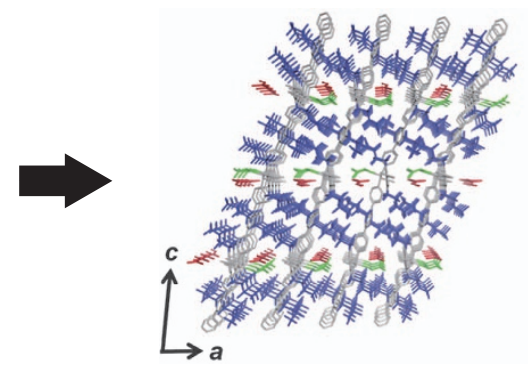<smiles>FC(F)(F)c1cc(-c2ccncc2)c(C(F)(F)F)cc1-c1ccncc1</smiles>

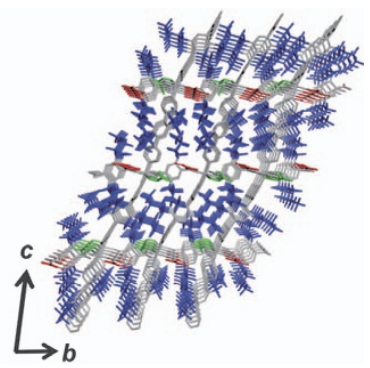

b<smiles>O=C(O)C(F)(F)C(F)(F)F</smiles>

$\mathrm{n}=3,7,9$

$+$<smiles>O=C(O)c1ccc(-c2cc(-c3ccc(C(=O)O)cc3)c3ccc4c(-c5ccc(C(=O)O)cc5)cc(-c5ccc(C(=O)O)cc5)c5ccc2c3c54)cc1</smiles>

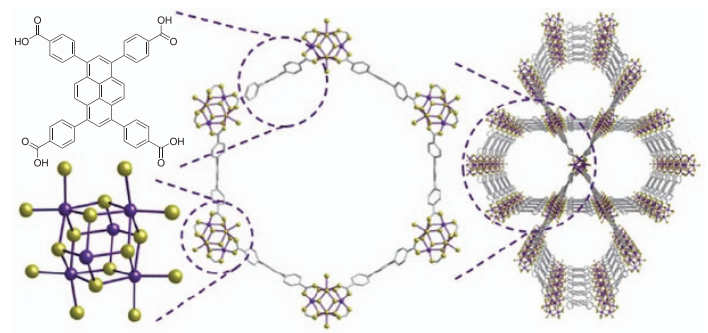

$\boldsymbol{0}=\mathrm{Zr} \quad \boldsymbol{O}=\mathrm{O},-\mathrm{OH} \quad \boldsymbol{0}=\mathrm{C}$
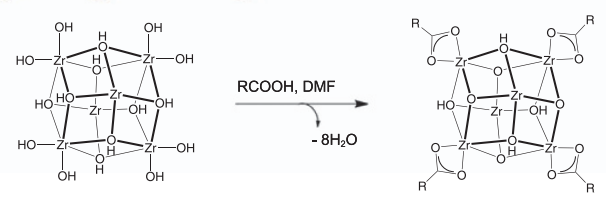

Figure 13 (a) Crystal structure of $\{[C \mathrm{Cu}(\mathrm{bpbtp})(\mathrm{L} 5)(\mathrm{DMF})] \cdot \mathrm{DMF}\}$. Perfluorobutyl groups are coloured blue. Reproduced from Jeon et al. ${ }^{44}$ (b) Crystal structure and solvent-assisted ligand incorporation in $\left[\mathrm{Zr}_{6}\left(\mu_{3}-\mathrm{OH}\right)_{8}(\mathrm{OH})_{8}(\mathrm{TBAPy})_{2}\right](\mathrm{NU}-1000)$. Reproduced from Deria et al. ${ }^{45}$

for the heat of adsorption than the parent NU-1000 with increasing the length of the perfluoroalkane chain and (2) the $\mathrm{Zr}_{6}$ cluster and perfluoroalkane synergistically acted as the primary $\mathrm{CO}_{2}$ adsorption sites. The $\mathrm{C}-\mathrm{F}$ dipole in the perfluoroalkane carboxylate contributed to the favorable $\mathrm{C}-\mathrm{F} \bullet \bullet \mathrm{CO}_{2}$ interaction.

\section{POSTSYNTHETIC TRIFLUOROMETHYL MODIFICATION OF MOF} USING A PLASMA-ENHANCED CHEMICAL VAPOR DEPOSITION Decoste et al. ${ }^{57}$ reported a unique technique to modify an internal pore surface of MOF with trifluoromethyl groups. The postsynthetic treatment of the famous three-dimensional hydrophilic MOF, $\left[\mathrm{Cu}_{3}(\text { btc })_{2}\right]$ (HKUST-1, $\mathrm{H}_{3}$ btc $=1,3,5$-benzenetricarboxylic acid), ${ }^{58}$ with a plasma-enhanced chemical vapor deposition of perfluorohexane yielded a hydrophobic form of HKUST-1 (herein referred to as 'HKUST-1 plasma'). The HKUST-1 plasma got $\mathrm{CF}_{3}$ groups on the surface of the pores with maintenance of the overall crystal structure of HKUST-1 and the presence of the $\mathrm{CF}_{3}$ groups had an important role in perfluorohexane loading. Thus, the HKUST-1 plasma with pefluorohexane guests showed an enhanced stability to ammonia and water and an enhanced ammonia adsorption capacity compared with untreated HKUST-1.

\section{CONCLUSION AND OUTLOOK}

In this review article, we organized the structures and porous properties of MOFs/PCPs decorated with fluorinated building blocks such as fluorine- or trifluoromethyl-functionalized organic bridging ligands, inorganic fluorinated anions and perfluoroalkanefunctionalized organic ligands. The manipulation of porous structures using fluorine-containing building blocks leads to fascinating porous properties such as high hydrophobicity, preferable adsorption for targeted gases, flexible pores and specific perfluoroarene-arene interaction. In addition, we expect that fluorine functionalization has great potential to give other novel and beneficial properties to $\mathrm{MOF} / \mathrm{PCPs}$.

The existence of high-energy $\mathrm{C}-\mathrm{H}$ and/or $\mathrm{O}-\mathrm{H}$ oscillators in luminescent coordination compounds causes a decrease in emission intensity. Utilization of fluorinated organic ligands with low-energy $\mathrm{C}-\mathrm{F}$ bonds is effective for reducing/eliminating the nonemissive process associated with vibrational relaxation. Chen et al. ${ }^{59}$ 
compared the luminescent properties of two three-dimensional MOFs, $\left\{\left[\mathrm{Er}_{2}(1,4-\mathrm{bdc})_{3}(\mathrm{DMF})_{2}\left(\mathrm{H}_{2} \mathrm{O}\right)\right] \bullet \mathrm{H}_{2} \mathrm{O}\right\}$ and $\left\{\left[\mathrm{Er}_{2}\right.\right.$ (tetrafluoroterephthalate $\left.\left.)_{3}(\mathrm{DMF})\left(\mathrm{H}_{2} \mathrm{O}\right)\right] \cdot \mathrm{DMF}\right\}$. The partially desolvated fluorinated MOF $\left.\left\{\left[\mathrm{Er}_{2} \text { (tetrafluoroterephthalate }\right)_{3}(\mathrm{DMF})\right] \cdot \mathrm{DMF}\right\}$ showed higher $\mathrm{Er}(\mathrm{III})-$ based emission intensity than the desolvated non-fluorinated MOF $\left[\mathrm{Er}_{2}(1,4-\mathrm{bdc})_{3}\right]$. The hfa (hexafluoroacetylacetonate) chelating ligand is also a good building unit for the construction of MOFs exhibiting strong emissions. Hasegawa and colleagues ${ }^{60}$ reported the onedimensional $\mathrm{Eu}(\mathrm{III})$ coordination polymers, $\left[\mathrm{Eu}(\mathrm{hfa})_{3}(\mathrm{~L})\right](\mathrm{L}=$ bidentate phosphane oxide ligands). In particular, a high-emission quantum yield $\left(\Phi_{\mathrm{Ln}}=83 \%\right.$ in the solid state) was observed in $\left[\mathrm{Eu}(\mathrm{hfa})_{3}(\mathrm{dppcz})\right]$ (dppcz $=3,6$-bis(diphenylphosphoryl)-9-phenylcarbazole). Although the luminescent properties given in this paragraph are not related to porous properties, it is expected that this strategy to use fluorinated ligands is available for the construction of luminescent MOFs showing a significant guest-responsive change in emission properties in future sensing devices.

Fine control of framework flexibility is one of the challenging issues in MOF/PCP chemistry. A solid-solution approach based on organic bridging ligands such as substituted dicarboxylates has been applied to tune the flexibility. ${ }^{61,62}$ Inorganic fluorinated monoanions have the potential to endow MOFs/PCPs with flexibility and the degree of flexibility is dependent on the kind of these monoanions. For example, we found inorganic monoanion-dependent acetone adsorption properties of porous assemblies of coordination complexes, $\left[\mathrm{Cu}(\mathrm{A})_{2}\right.$ (pyridine $\left.)_{4}\right]\left(\mathrm{A}=\mathrm{PF}_{6}^{-}, \mathrm{BF}_{4}^{-}, \mathrm{CF}_{3} \mathrm{SO}_{3}^{-}\right.$and $\left.\mathrm{CH}_{3} \mathrm{SO}_{3}^{-}\right){ }^{63}$ The desolvated forms had no pores and showed no $\mathrm{N}_{2}$ and $\mathrm{CO}_{2}$ adsorption at all. However, the adsorption isotherms for acetone at $283 \mathrm{~K}$ clearly indicated that the porous assemblies of coordination complexes with $\mathrm{PF}_{6}$ or $\mathrm{BF}_{4}$ monoanions took in acetone guests with structural changes, whereas the porous assemblies of coordination complexes with $\mathrm{CF}_{3} \mathrm{SO}_{3}$ or $\mathrm{CH}_{3} \mathrm{SO}_{3}$ monoanions exhibited no response to acetone. Furthermore, these monoanions are often coordinated to the metal centers in a monodentate manner, which is effective in an unalterable framework topology during complete or partial anion displacement. We believe that these characteristics in inorganic fluorinated monoanions contribute to the controllable flexibility in MOFs/PCPs by mixing more than two kinds of monoanions.

Charge- and electron-transfer MOFs/PCPs composed of electron donor and acceptor units may show fascinating electronic properties (magnetic, conductive and ferroelectric properties) coupled with porous properties. ${ }^{64}$ Modification of organic ligands by fluorine atom with the highest electronegativity and small van der Waals radius enables to drastically change the degree of charge/electron transfer with less effect in steric hindrance, resulting in a fine tuning of electronic structures and properties. A series of electronically active carboxylate-bridged paddle-wheel $\mathrm{Ru}$ dimers can be utilized as an electron-donor building unit in MOFs/PCPs frameworks with electron-acceptor building units.

In addition, it is important to provide new synthetic methods to obtain fluorine-functionalized MOFs/PCPs. Partial incorporation of fluorine-containing molecules into pores of MOFs/PCPs may be a new approach to obtain fluorine-dominated porous properties. Uemura and colleagues ${ }^{65}$ hint at the possibility of this synthetic approach. Oligo(vinylidene fluoride) was confined in $1 \times 1 \mathrm{~nm}^{2}$ pores of the three-dimensional MOF, $[\mathrm{Tb}(1,3,5$-benzenetrisbenzoate $)],{ }^{66}$ without any fluorine substituents to elucidate the dynamics of oligo(vinylidene fluoride) in restricted space. Although the parent MOF showed a typical type $\mathrm{I}_{2}$ isotherm with the Brunauer-Emmett-Teller specific surface area of $730-930 \mathrm{~m}^{2} \mathrm{~g}^{-1}$, the obtained composite adsorbed negligible amount of $\mathrm{N}_{2}$ gas, indicating no accessible pores after the incorporation of oligo(vinylidene fluoride). However, we expect that if pores can be filled with an appropriate amount of fluorine-containing molecules, the composite may retain sufficient accessibility for other guests with a fluorine-modified pore surface. Partial incorporation of ionic liquids with inorganic fluorinated anions into MOFs/PCPs is also effective for creating a fluorine-modified pore surface. ${ }^{42}$

Finally, we anticipate that this review will attract much attention among not only MOF/PCP scientists but also many researchers involved in other scientific fields and provide opportunities to investigate new and/or reported fluorine-functionalized MOFs/PCPs towards future applications.

\section{CONFLICT OF INTEREST}

The authors declare no conflict of interest.

\section{ACKNOWLEDGEMENTS}

This work was supported by the 'ACCEL Project' (JPMJAC1302) from the Japan Science and Technology Agency, Creative Research Institution at Hokkaido University and the Dynamic Alliance for Open Innovation Bridging Human, Environment and Materials from the Ministry of Education, Culture, Sports, Science and Technology.

\section{PUBLISHER'S NOTE}

Springer Nature remains neutral with regard to jurisdictional claims in published maps and institutional affiliations.

1 Kitagawa, S., Kitaura, R. \& Noro, S. Functional porous coordination polymers. Angew. Chem. Int. Ed. 43, 2334-2375 (2004).

2 Yaghi, O. M., O'Keeffe, M., Ockwig, N. W., Chae, H. K., Eddaoudi, M. \& Kim, J. Reticular synthesis and the design of new materials. Nature 423, 705-714 (2003).

3 Férey, G. Hybrid porous solids: past, present, future. Chem. Soc. Rev. 37, 191-214 (2008).

4 Furukawa, H., Ko, N., Go, Y. B., Aratani, N., Choi, S. B., Choi, E., Yazaydin, A. Ö., Snurr, R. Q., O'Keeffe, M., Kim, J. \& Yaghi, O. M. Ultrahigh porosity in metal-organic frameworks. Science 329, 424-428 (2010).

5 Serre, C., Millange, F., Thouvenot, C., Noguès, M., Marsolier, G., Louër, D. \& Férey, G. Very large breathing effect in the first nanporous chromium(III)-based solids: MIL-53 or $\mathrm{Cr}^{\prime \prime \prime}(\mathrm{OH})\left\{\mathrm{O}_{2} \mathrm{C}-\mathrm{C}_{6} \mathrm{H}_{4}-\mathrm{CO}_{2}\right\}\left\{\mathrm{HO}_{2} \mathrm{C}-\mathrm{C}_{6} \mathrm{H}_{4}-\mathrm{CO}_{2} \mathrm{H}_{x_{x}} \bullet \mathrm{H}_{2} \mathrm{O}_{y}\right.$. J. Am. Chem. Soc. 124, 13519-13526 (2002).

6 Sato, H., Kosaka, W., Matsuda, R., Hori, A., Hijikata, Y., Belosludov, R. V., Sakaki, S., Takata, M. \& Kitagawa, S. Self-accelerating CO sorption in a soft nanoporous crystal. Science 343, 167-170 (2014).

7 Pachfule, P. \& Banerjee, R. in Encyclopedia of Inorganic and Bioinorganic Chemistry, 1-124. (John Wiley \& Sons, Ltd., 2014).

8 Kasai, K. \& Fujita, M. Guest-dependent flexible coordination networks with fluorinated ligands. Chem. Eur. J. 13, 3089-3105 (2007).

9 Hulvey, Z., Falcao, E. H. L., Eckert, J. \& Cheetham, A. K. Enhanced $\mathrm{H}_{2}$ adsorption enthalpy in the low-surface area, partially fluorinated coordination polymer $\mathrm{Zn}_{5}$ (triazole) $)_{6}$ (tetrafluoroterephthalate $)_{2}\left(\mathrm{H}_{2} \mathrm{O}\right)_{2} \bullet 4 \mathrm{H}_{2} \mathrm{O}$. J. Mater. Chem. 19, 4307-4309 (2009)

10 Forrest, K. A., Pham, T., Georgies, P. A., Pinzan, F., Cioce, C. R., Unruh, T., Eckert, J. \& Space, B. Investigating $\mathrm{H}_{2}$ sorption in a fluorinated metal-organic framework with small pores through molecular simulation and inelastic neutron scattering. Langmuir 31, 7328-7336 (2015).

11 Zhang, D.-S., Chang, Z., Li, Y.-F., Jiang, Z.-Y., Xuan, Z.-H., Zhang, Y.-H., Li, J.-R., Chen, Q., Hu, T.-L. \& Bu, X.-H. Fluorous metal-organic frameworks with enhanced stability and high $\mathrm{H}_{2} / \mathrm{CO}_{2}$ storage capacities. Sci. Rep. 3, 3312 (2013).

12 Bae, Y.-S., Farha, O. K., Hupp, J. T. \& Snurr, R. Q. Enhancement of $\mathrm{CO}_{2} / \mathrm{N}_{2}$ selectivity in a metal-organic framework by cavity modification. J. Mater. Chem. 19, 2131-2134 (2009)

13 Monge, A., Snejko, N., Gutiérrez-Puebla, E., Medina, M., Cascales, C., Ruiz-Valero, C., Iglesias, M. \& Gómez-Lor, B. One teflon ${ }^{\circledast}$-like channelled nanoporous polymer with a chiral and new uninodal 4-connected net: sorption and catalytic properties. Chem. Commun. 1291-1293 (2005).

14 Mukherjee, S., Kansara, A. M., Saha, D., Gonnade, R., Mullangi, D., Manna, B., Desai, A. V., Thorat, S. H., Singh, P. S., Mukherjee, A. \& Ghosh, S. K. An ultrahydrophobic fluorous metal-organic framework derived recyclable composite as a promising platform to tackle marine oil spills. Chem. Eur. J. 22, 10937-10943 (2016). 
15 Yang, C., Kaipa, U., Mather, Q. Z., Wang, X., Nesterov, V., Venero, A. F. \& Omary, M. A. Fluorous metal-organic frameworks with superior adsorptioin and hydrophobic properties toward oil spill cleanup and hydrocarbon storage. J. Am. Chem. Soc. 133 18094-18097 (2011).

16 Nijem, N., Canepa, P., Kaipa, U., Tan, K., Roodenko, K., Tekarli, S., Halbert, J., Oswald, I. W. H., Arvapally, R. K., Yang, C., Thonhauser, T., Omary, M. A. \& Chabal, Y. J. Water cluster confinement and methane adsorption in the hydrophobic cavities of a fluorinated metal-organic framework. J. Am. Chem. Soc. 135, 12615-12626 (2013).

17 Drache, F., Bon, V., Senkovska, I., Marschelke, C., Synytska, A. \& Kaskel, S. Postsynthetic inner-surface functionalization of the highly stable zirconium-based metal-organic framework DUT-67. Inorg. Chem. 55, 7206-7213 (2016).

18 Subramanian, S. \& Zaworotko, M. J. Porous solids by design: [Zn $\left.\left(4,4^{\prime}-b p y\right)_{2}\left(\mathrm{SiF}_{6}\right)\right]$ $n^{\bullet} \times \mathrm{DMF}$, a single framework octahedral coordination polymer with large square channels. Angew. Chem. Int. Ed. 34, 2127-2129 (1995).

19 Noro, S., Kitagawa, S., Kondo, M. \& Seki, K. A new, methane adsorbent, porous coordination polymer $\left[\left\{\mathrm{CuSiF}_{6}\left(4,4^{\prime} \text {-bipyridine }\right)_{2}\right\}_{n}\right]$. Angew. Chem. Int. Ed. 39, 2082-2084 (2000).

20 Burd, S. D., Ma, S., Perman, J. A., Sikora, B. J., Snurr, R. Q., Thallapally, P. K., Tian, J., Wojtas, L. \& Zaworotko, M. J. Highly selective carbon dioxide uptake by [Cu $\left.(\text { bpy- } n)_{2}\left(\mathrm{SiF}_{6}\right)\right]$ (bpy-1=4,4'-Bipyridine; bpy-2=1,2-Bis(4-pyridyl)ethene. J. Am. Chem. Soc. 134, 3663-3666 (2012).

21 Cui, X., Chen, K., Xing, H., Yang, Q., Krishna, R., Bao, Z., Wu, H., Zhou, W., Dong, X., Han, Y., Li, B., Ren, Q., Zaworotko, M. J. \& Chen, B. Pore chemistry and size control in hybrid porous materials for acetylene capture from ethylene. Science 353, 141-144 (2016).

22 Nugent, P., Rhodus, V., Pham, T., Tudor, B., Forrest, K., Wojtas, L., Space, B. \& Zaworotko, M. Enhancement of $\mathrm{CO}_{2}$ selectivity in a pillared pcu MOM platform through pillar substitution. Chem. Commun. 49, 1606-1608 (2013).

23 Nugent, P., Belmabkhout, Y., Burd, S. D., Cairns, A. J., Luebke, R., Forrest, K., Pham, T., Ma, S., Space, B., Wojtas, L., Eddaoudi, M. \& Zaworotko, M. J. Porous materials with optimal adsorption thermodynamics and kinetics for $\mathrm{CO}_{2}$ separation. Nature 495, 80-84 (2013).

24 Chen, K.-J., Scott, H. S., Madden, D. G., Pham, T., Kumar, A., Bajpai, A., Lusi, M., Forrest, K. A., Space, B., Perry, J. J. IV \& Zaworotko, M. J. Benchmark $\mathrm{C}_{2} \mathrm{H}_{2} / \mathrm{CO}_{2}$ and $\mathrm{CO}_{2} / \mathrm{C}_{2} \mathrm{H}_{2}$ separation by two closely related hybrid ultramicroporous materials. Chem. 1 , 753-765 (2016).

25 Noro, S., Kitaura, R., Kondo, M., Kitagawa, S., Ishii, T., Matsuzaka, H. \& Yamashita, M Framework engineering by anions and porous functionalities of $\mathrm{Cu}(\mathrm{II}) / 4,4^{\prime}$-bpy coordination polymers. J. Am. Chem. Soc. 124, 2568-2583 (2002).

26 Elsaidi, S. K., Mohamed, M. H., Schaef, H. T., Kumar, A., Lusi, M., Pham, T., Forrest, K. A., Space, B., Xu, W., Halder, G. J., Liu, J., Zaworotko, M. J. \& Thallapally, P. K. Hydrophobic pillared square grids for selective removal of $\mathrm{CO}_{2}$ from simulated flue gas. Chem. Commun. 51, 15530-15533 (2015).

27 Elsaidi, S. K., Mohamed, M. H., Simon, C. M., Braun, E., Pham, T., Forrest, K. A., Xu, W., Banerjee, D., Space, B., Zaworotko, M. J. \& Thallapally, P. K. Effect of ring rotation upon gas adsorption in SIFSIX-3-M $(\mathrm{M}=\mathrm{Fe}, \mathrm{Ni})$ pillared square grid networks. Chem. Sci. 8, 2373-2380 (2017).

28 Elsaidi, S. K., Mohamed, M. H., Pham, T., Hussein, T., Wojtas, L., Zaworotko, M. J. \& Space, B. Crystal engineering of a 4,6-c fsc platform that can serve as a carbon dioxide single-molecule trap. Cryst. Growth Des. 16 1071-1080 (2016).

29 Cadiau, A., Adil, K., Bhatt, P. M., Belmabkhout, Y. \& Eddaoudi, M. A metal-organic framework-based splitter for separating propylene from propane. Science 353, 137-140 (2016).

30 Bhatt, P. M., Belmabkhout, Y., Cadiau, A., Adil, K., Shekhah, O., Shkurenko, A., Barbour, L. J. \& Eddaoudi, M. A fine-tuned fluorinated MOF addresses the needs for trace $\mathrm{CO}_{2}$ removal and air capture using physisorption. J. Am. Chem. Soc. 138, 9301-9307 (2016).

31 Kondo, A., Noguchi, H., Ohnishi, S., Kajiro, H., Tohdoh, A., Hattori, Y., Xu, W.-C. Tanaka, H., Konoh, H. \& Kaneko, K. Novel expansion/shrinkage modulation of 2D layered MOF triggered by clathrate formation with $\mathrm{CO}_{2}$ molecules. Nano Lett. 6, 2581-2584 (2006).

32 Kondo, A., Noguchi, H., Carlucci, L., Proserpio, D. M., Ciani, G., Kajiro, H., Ohba, T., Kanoh, H. \& Kaneko, K. Double-step gas sorption of a two-dimensional metal-organic framework. J. Am. Chem. Soc. 129, 12362-12363 (2007).

33 Noro, S., Hijikata, Y., Inukai, M., Fukushima, T., Horike, S., Higuchi, M., Kitagawa, S., Akutagawa, T. \& Nakamura, T. Highly selective $\mathrm{CO}_{2}$ adsorption accompanied with lowenergy regeneration in a two-dimensional $\mathrm{Cu}(\mathrm{II})$ porous coordination polymer with inorganic fluorinated $\mathrm{PF}_{6}{ }^{-}$anions. Inorg. Chem. 52, 280-285 (2013).

34 Kondo, A., Chinen, A., Kajiro, H., Nakagawa, T., Kato, K., Takata, M., Hattori, Y., Okino, F., Ohba, T., Kaneko, K. \& Kanoh, H. Metal-ion-dependent gas sorptivity of elastic layer-structured MOFs. Chem. Eur. J. 15, 7549-7553 (2009).

35 Noro, S., Tanaka, D., Sakamoto, H., Shimomura, S., Kitagawa, S., Takeda, S., Uemura, K., Kita, H., Akutagawa, T. \& Nakamura, T. Selective gas adsorption in onedimensional, flexible Cull coordination polymers with polar units. Chem. Mater. 21 3346-3355 (2009).

36 Noro, S., Akutagawa, T. \& Nakamura, T. Selective separation of larger molecules from a Lewis-base mixture by flexible one-dimensional $\mathrm{Cu}(\mathrm{II})$ coordination polymer with shaperecognizing space. Chem. Commun. 46, 3134-3136 (2010).

37 Noro, S., Ochi, R., Inubushi, Y., Kubo, K. \& Nakamura, T. $\mathrm{CH}_{4} / \mathrm{CO}_{2}$ and $\mathrm{CH}_{4} / \mathrm{C}_{2} \mathrm{H}_{6}$ gas separation using a flexible one-dimensional Copper(II) porous coordination polymer. Microporous Mesoporous Mater. 216, 92-96 (2015).
38 Kotani, R., Kondo, A. \& Maeda, K. Gate adsorption of $\mathrm{CO}_{2}$ on a flexible one-dimensiona copper-based coordination polymer crystal. Chem. Commun. 48 11316-11318 (2012)

39 Noro, S., Matsuda, R., Hijikata, Y., Inubushi, Y., Takeda, S., Kitagawa, S., Takahashi, Y., Yoshitake, M., Kubo, K. \& Nakamura, T. High $\mathrm{CO}_{2} / \mathrm{CH}_{4}$ selectivity of a flexible copper(II) porous coordination polymer under humid conditions. ChemPlusChem. 80, 1517-1524 (2015).

40 Fukuhara, K., Noro, S., Sugimoto, K., Akutagawa, T., Kubo, K. \& Nakamura, T. Porous coordination polymer polymorphs with different flexible pores using structurally flexible and bent 1,3-Bis(4-pyridyl)propane ligand. Inorg. Chem. 52 4229-4237 (2013).

41 Noro, S., Fukuhara, K., Hijikata, Y., Kubo, K. \& Nakamura, T. Rational synthesis of a porous copper(II) coordination polymer bridged by weak Lewis-base inorganic monoanions using an anion-mixing method. Inorg. Chem. 52, 5630-5632 (2013).

42 Fujie, K., Otsubo, K., Ikeda, R., Yamada, T. \& Kitagawa, H. Low temperature ionic conductor: ionic liquid incorporated within a metal-organic framework. Chem. Sci. 6, 4306-4310 (2015)

43 Jang, M., Yamaguchi, T., Ohara, K., Kawano, M. \& Fujita, M. Fluorous pores in coordination networks. Chem. Asian J. 4, 1524-1526 (2009).

44 Jeon, H. J., Matsuda, R., Kanoo, P., Kajiro, H., Li, L., Sato, H., Zheng, Y. \& Kitagawa, $\mathrm{S}$. The densely fluorinated nanospace of a porous coordination polymer composed of perfluorobutyl-functionalized ligands. Chem. Commun. 50, 10861-10863 (2014).

45 Deria, P., Mondloch, J. E., Tylianakis, E., Ghosh, P., Bury, W., Snurr, R. Q., Hupp, J. T. \& Farha, O. K. Perfluoroalkane functionalization of NU-1000 via solvent-assisted ligand incorporation: synthesis and $\mathrm{CO}_{2}$ adsorption studies. J. Am. Chem. Soc. 135, 16801-16804 (2013).

46 Williams, J. H. The molecular electric quadrupole moment and solid-state architecture. Acc. Chem. Res. 26, 593-598 (1993).

47 Kasai, K., Aoyagi, M. \& Fujita, M. Flexible coordination networks with fluorinated backbones. Remarkable ability for induced-fit enclathration of organic molecules. J. Am. Chem. Soc. 122, 2140-2141 (2000).

48 Desiraju, G. R. \& Steiner, T. The Weak Hydrogen Bond (Oxford University Press Inc.: New York, USA, 2001).

49 Yang, C., Wang, X. \& Omary, M. A. Fluorous metal-organic frameworks for high-density gas adsorption. J. Am. Chem. Soc. 129, 15454-15455 (2007).

50 Shekhah, O., Belmabkhout, Y., Adil, K., Bhatt, P. M., Cairns, A. J. \& Eddaoudi, M. A facile solvent-free synthesis route for the assembly of a highly $\mathrm{CO}_{2}$ selective and $\mathrm{H}_{2} \mathrm{~S}$ tolerant NiSIFSIX metal-organic framework. Chem. Commun. 51, 13595-13598 (2015).

51 Wilkes, J. S. A short history of ionic liquids-from molten salts to neoteric solvents. Green Chem. 4, 73-80 (2002).

52 Blake, A. J., Hill, S. J., Hubberstey, P. \& Li, W.-S. Rectangular grid two-dimensional sheets of copper(II) bridged by both co-ordinated and hydrogen bonded 4,4'-bipyridine $\left(4,4^{\prime}\right.$-bipy) in $\left[\mathrm{Cu}\left(\mu-4,4^{\prime}\right.\right.$-bipy $\left.)\left(\mathrm{H}_{2} \mathrm{O}\right)_{2}\left(\mathrm{FBF}_{3}\right)_{2}\right] \cdot 4,4^{\prime}$-bipy. J. Chem. Soc. Dalton Trans. 913-914 (1997).

53 Hiraide, S., Tanaka, H. \& Miyahara, M. T. Understanding gate adsorption behaviour of $\mathrm{CO}_{2}$ on elastic layer-structured metal-organic framework-11. Dalton Trans. 45, 4193-4202 (2016)

54 Noro, S., Horike, S., Tanaka, D., Kitagawa, S., Akutagawa, T. \& Nakamura, T. Flexible and shape-selective guest binding at $\mathrm{Cu}^{\prime l}$ axial sites in 1-dimensional Cull-1,2-bis(4-pyridyl)ethane coordination polymers. Inorg. Chem. 45 9290-9300 (2006)

55 Tanaka, H., Hiraide, S., Kondo, A. \& Miyahara, M. T. Modeling and visualization of $\mathrm{CO}_{2}$ adsorption on elastic layer-structured metal-organic framework-11: toward a better understanding of gate adsorption behavior. J. Phys. Chem. C 119, 11533-11543 (2015).

56 Suzuki, T., Kotani, R., Kondo, A. \& Maeda, K. Structural investigation of a flexible MOF $\left[\mathrm{Cu}\left(\mathrm{BF}_{4}\right)_{2} \text { (1,3-bis(4-pyridyl)propane) }\right)_{2}$ ] showing selective gate adsorption with dynamic pore-opening/pore-closing processes. J. Phys. Chem. C 120, 21571-21579 (2016).

57 Decoste, J. B., Peterson, G. W., Smith, M. W., Stone, C. A. \& Willis, C. R. Enhanced stability of Cu-BTC MOF via perfluorohexane plasma-enhanced chemical vapor deposition. J. Am. Chem. Soc. 134, 1486-1489 (2012).

58 Chui, S. S.-Y., Lo, S. M.-F., Charmant, J. P. H., Orpen, A. G. \& Williams, I. D. A chemically functionalizable nanoporous material $\left[\mathrm{Cu}_{3}(\mathrm{TMA})_{2}\left(\mathrm{H}_{2} \mathrm{O}\right)_{3}\right]_{n}$. Science 50 1148-1150 (1999).

59 Chen, B., Yang, Y., Zapata, F., Qian, G., Luo, Y., Zhang, J. \& Lobkovsky, E. B. Enhanced near-infrared-luminescence in an erbium tetrafluoroterephthalate framework. Inorg. Chem. 45, 8882-8886 (2006).

60 Miyata, K., Ohba, T., Kobayashi, A., Kato, M., Nakanishi, T., Fushimi, K. \& Hasegawa, Y. Thermostable organo-phosphor: low-vibrational coordination polymers that exhibit different intermoleculer interactions. ChemPlusChem 77, 277-280 (2012).

61 Fukushima, T., Horike, S., Inubushi, Y., Nakagawa, K., Kubota, Y., Takata, M. \& Kitagawa, S. Solid solutions of soft porous coordination polymers: fine-tuning of gas adsorption properties. Angew. Chem. Int. Ed. 49, 4820-4824 (2010).

62 Schwedler, I., Henke, S., Wharmby, M. T., Bajpe, S. R., Cheetham, A. K. \& Fischer, R. A. Mixed-linker solid solutions of functionalized pillared-layer MOFs-adjusting structural flexibility, gas sorption, and thermal responsiveness. Dalton Trans. 45, 4230-4241 (2016). 
63 Noro, S., Fukuhara, K., Sugimoto, K., Hijikata, Y., Kubo, K. \& Nakamura, T. Aniondependent host-guest properties of porous assemblies of coordination complexes (PACs), $\left[\mathrm{Cu}(\mathrm{A})_{2}(\mathrm{py})_{4}\right]\left(\mathrm{A}=\mathrm{PF}_{6}, \mathrm{BF}_{4}, \mathrm{CF}_{3} \mathrm{SO}_{3}\right.$, and $\mathrm{CH}_{3} \mathrm{SO}_{3}$; py= pyridine), based on Werner-type copper(II) complexes in the solid state. Dalton Trans. 42, 11100-11110 (2013).

64 Miyasaka, H. Control of charge transfer in donor/acceptor metal-organic frameworks. Acc. Chem. Res. 46, 248-257 (2013).

65 Yanai, N., Uemura, T., Kosaka, W., Matsuda, R., Kodani, T., Koh, Meiten, Kanemura, T. \& Kitagawa, S. Inclusion and dielectric properties of a vinylidene fluoride oligomer in coordination nanochannels. Dalton Trans. 41, 4195-4198 (2012).

66 Devic, T., Serre, C., Audebrand, N., Marrot, J. \& Férey, G. MIL-103, a 3-D lanthanidebased metal organic framework with large one-dimensional tunnels and a high surface area. J. Am. Chem. Soc. 127, 12788-12789 (2005). (c) (i) This work is licensed under a Creative Commons Attribution 4.0 International License. The images or other third party material in this article are included in the article's Creative Commons license, unless indicated otherwise in the credit line; if the material is not included under the Creative Commons license, users will need to obtain permission from the license holder to reproduce the material. To view a copy of this license, visit http:// creativecommons.org/licenses/by/4.0/

(C) The Author(s) 2017 